Portland State University

PDXScholar

\title{
"An I don't give a damn 'bout my bad reputation": The Effects of Family Type and Patriarchy in the Home on Female Adolescent Delinquency and Mental Health
}

Stephanie-Kaye Guenther

Portland State University

Follow this and additional works at: https://pdxscholar.library.pdx.edu/open_access_etds Let us know how access to this document benefits you.

\section{Recommended Citation}

Guenther, Stephanie-Kaye, "'An I don't give a damn 'bout my bad reputation": The Effects of Family Type and Patriarchy in the Home on Female Adolescent Delinquency and Mental Health" (2011). Dissertations and Theses. Paper 296.

https://doi.org/10.15760/etd.296

This Thesis is brought to you for free and open access. It has been accepted for inclusion in Dissertations and Theses by an authorized administrator of PDXScholar. Please contact us if we can make this document more accessible: pdxscholar@pdx.edu. 
"An I don't give a damn 'bout my bad reputation": The Effects of Family Type and Patriarchy in the Home on Female Adolescent Delinquency and Mental Health

by

Stephanie-Kaye Guenther

A thesis submitted in partial fulfillment of the requirements for the degree of

\author{
Master of Science \\ in \\ Sociology
}

Thesis Committee:

Melissa Thompson Chair

Lindsey Wilkinson

Hyeyoung Woo

Portland State University

2011 


\begin{abstract}
This study examined the connection between household type and delinquency and depressive symptoms for female adolescents. The present study draws its claims from Power-control theory which, at its most abstract level, predicts gender differences in delinquency based on the level of patriarchy in the family and the theoretical works of Sarah Rosenfield, who argues that it is the over control of females that causes them to have higher rates depression than males. This study hoped to build on research that links differences in family type and parental control to sex differences in delinquency by using the Power-control theory to look depressive symptoms among female adolescents. Past studies looking at female delinquency attempt to understand why females are under representative in crime statistics when compared to their male counterparts. These studies focus most of the attention on the social control placed over females.

Using multilevel logistic and ordinary least squares regression models, this thesis amid to contribute to a growing pool of research on the sociology of mental health and theories delinquency. Using the National Longitudinal Study of Adolescent Health, the findings showed that, contrary to claims made by power-control theory, patriarchal family did not predict delinquent behavior or depressive symptoms for female adolescents. Further analysis included an instrument of control, parental attachment, risk perceptions and found significant results. Race was also significant in several models. The parent-daughter relationship was most significant in predicting outcomes of depressive symptoms and delinquent behavior. Those who reported close
\end{abstract}


relationships with their parents were less likely to report depressive symptoms and delinquency behavior. 
Table of Contents

Abstract

List of Tables $\quad$ V

List of Figures

$\begin{array}{ll}\text { Chapter 1: Introduction } & 1\end{array}$

Chapter 2: Literature Review and Theoretical Framework 6

Hagan's Power-Control Theory 6

$\begin{array}{ll}\text { A Common Etiology } & 10\end{array}$

$\begin{array}{ll}\text { Sarah Rosenfield } & 11\end{array}$

$\begin{array}{ll}\text { Past Research } & 14\end{array}$

$\begin{array}{ll}\text { Chapter 3: Methodology } & 21\end{array}$

$\begin{array}{ll}\text { Chapter 4: Findings } & 37\end{array}$

$\begin{array}{ll}\text { Descriptive Statistics } & 37\end{array}$

Bivariate Statistic $\quad 38$

$\begin{array}{ll}\text { Multivariate Statistics } & 41\end{array}$

$\begin{array}{ll}\text { Chapter 5: Conclusion } & 49\end{array}$

$\begin{array}{ll}\text { Discussion } & 49\end{array}$

$\begin{array}{ll}\text { Strengths } & 53\end{array}$

$\begin{array}{ll}\text { Limitations } & 54\end{array}$

Future Research $\quad 56$ 
Conclusion

References 
List of Tables

Table 3.1 Scale Items and Alpha Coefficients 26

Table 3.2 Parent's Occupational Prestige Score and Percents 29

Table 4.1 Distributions of Weighted Variables and Descriptive Statistics 35

Table 4.2 Cross tabulation of Family Type and Delinquent Behavior 38

Table 4.3 Cross tabulation of Race and Delinquent Behavior 39

Table 4.4 Cross tabulation of Race and Family Type $\quad 40$

Table 4.5 Negative Binomial Logistic Regression on Delinquency $\quad 40$

Table 4.6 OLS Regression on Depression $\quad 47$

Table 5.1 OLS Delinquency Regressed on Relational Control 48 


\section{LIST OF FIGURES}

FIGURE 3.1 Skewed Results of Delinquency 


\section{Chapter 1: Introduction}

During adolescence girls and boys separate in their response to social stressors (Allison et al., 1997). Females begin to demonstrate higher levels of depression when compared to males and males begin to engage in more anti-social behavior (Aarons et al., 2001; Garland et al., 2001) Theorists suggest that adolescents experience intensified gendered socialization since the physical changes they experience cause others to see them as socially identified "women" and "men" (Rosenfield 1999). During the lifetime period of adolescence it has been suggested by Hagan and colleagues that young people first try out adult roles and begin to behave in culturally specific gender roles and develop their gender identity. (Hagan and Foster 2001) Adolescence is an ideal period to study mental health and delinquency since they tend to emerge at this period of life. Studies of mental health disorders among general populations reveal prevalence rates between $14 \%$ and $22 \%$ of youth suffering from one or more mental illness (Kazdin 2000 and Rutter 1989). This research is interested in the period of life commonly referred to as adolescence. This period is usually considered to be 13 to 18 years of age.

Some research has shown that parents have more influence on early adolescent behaviors than peers because they act as the primary socializers (Miller et al. 2005; Walker 2005). It has also been suggested that parental bonds for females is strong in predicting delinquent behavior (Kerpelman \&Smith-Adcock, 2005). Contemporary research suggests that there is growing awareness in the possibility of a common origin for delinquent behavior and mental illness (Hagan et al., 2002; Rosenfield et al., 
2005). The current study would like to expand on that research. The theoretical framework that may give insight on the issue of gender difference in delinquent behavior is the Power-Control theory as developed by Hagan and colleagues (Hagan, 1989; Hagan, Gillis, and Simpson, 1985, 1990, 1993; Hagan, Simpson \&Gillis, 1987; McCarthy, Hagan and Woodward, 1999). Power-control theory explains the gender gap in delinquency by assessing family type.

The power-Control asserts that within the family, parents reproduce the power relationships they act out in the workplace. Power-Control theory suggests that adolescent's parent's class position, as defined through their work, influences their delinquent behavior. The patriarchal family structure is identified when a father acts in the traditional way of being the sole wage earner and a mother has only an unskilled job or does not work for pay. A patriarchal family is defined by the low occupational authority of the mother and the high occupational authority of the father. Daughters then are socialized to be like their mothers, which prepares them for lives in domestic labor and consumption. Thus, sons are encouraged and permitted to take risks and daughters are closely monitored so that delinquent behavior is unlikely (Hagan 1987). In the alternative family, the egalitarian family, the treatment of sons and daughters is considered more or less equal in terms of socialization and control. Female children are treated as equals to their male counterparts, risk taking and delinquent behavior is similar. (Hagan 1987) The over control of daughters discourages risk taking behavior and independence. For example, parents may convince their daughters that the world is an unsafe place (Rosenfield 1999). Such cultural messages suggest to females that 
they are unable to fend for themselves. Parents justify the high levels of social control placed on daughters when compared to sons, by themselves internalizing these sexist cultural values (Rosenfield 1999; Hagan and Foster 2001; Gilligan 1982; Heifer et al. 2006). This treatment is suggested by Rosenfield to cause females to feel as if they have little control over the world. She says that this can be particularly damaging since control is valued in society (Rosenfield 1999). This may lead women to have feelings of hopelessness and predispose them feelings of helplessness and low self-worth. This research is motivated and interested in such a connection between delinquency and mental health primarily by work done by Sarah Rosenfield $(1995,1999)$ and an interest in more specifically expanding assertions about patriarchy in the home as suggested by the power-control theory (1985). This research is interested in how the over-control of females in the home affects delinquency and mental health for female adolescents.

A secondary analysis was performed on data from the first wave of the Longitudinal Adolescent Health Survey, a commonly used and well-respected nationally representative survey. By using John Hagan's (1985) power-control theory of delinquency that suggests family type will predict delinquent outcomes for adolescent females and the theoretical notions of Sarah Rosenfield, this study proposes that family type can predict delinquent behavior and depression for female adolescents. These thesis test assertions by Rosenfield and looks at attitudes towards risk taking behaviors, which adds to an existing gap in the literature which suggest that risk-taking has positive outcomes for female adolescents. In the original form of 
power-control theory Hagan and colleagues were interested in the "traditional" form of the family meaning: one father and one mother (1985). While this family type is not as culturally popular or present as it was in 1985 , this research is interested in testing the original form of the power-control theory as a starting point for future research interested in a common etiology of delinquent behavior and mental health and interested in how patriarchy through the family may influence mental health outcomes for female adolescents.

Chapter 2 explains Hagan and colleague's theory (Hagan, 1985) power-control theory, the theoretical framework guiding this thesis, in further detail. Also included in this chapter is the work of Sarah Rosenfield and how her work is added to the powercontrol theory to test for a common etiology of mental illness. The relevant literature is also outlined in this chapter and a list of hypothesis is examined at the conclusion of chapter 2.

Chapter 3 explains the methodology used to examine the effects of the theoretically relevant variables and how they influence delinquency and mental health. A detailed description of the data set is included in this chapter and a discussion of the analysis and how the complicated nature of the data was addressed. Also included in Chapter 3 is detailed information on variable construction, how the final instruments vary from the original data set, an explanation and rationale for why the variables were chosen, and how these variables were operationalized.

Chapter 4 begins with descriptive statistics for each variable used in this thesis. The research question and hypotheses are addressed by bivariate and multivariate 
analyses. Multivariate ordinary least squares regression and multivariate negative binomial logistic regressions are preformed to explain how family type and variables important to the power-control theory affect female adolescent delinquency and mental health, and to test and see which relationship explains the most after controlling for all other variables.

Chapter 5 discusses the relevant findings of this thesis and how this research contributed to a larger body of research interested in the common etiology of mental health and delinquency. Also discussed in this chapter are the limitations of this thesis and how future studies should address such restrictions. The strengths of this thesis are highlighted and a discussion of future research is found in the concluding chapter. 


\section{Chapter 2: Theoretical Frameworks and Literature Review}

\section{John Hagan's Power-Control Theory}

The power-control theory aims to explain the low rates of females engaging in delinquent behavior as class relations through assessing family type and power and control within the family. In the original form of power-control theory, Hagan and colleagues were interested in the "traditional" form of the family meaning: one father and one mother which was seen as "typical" for the time due to idealization within a broad cultural context (1985). This family type was ideal for the theory which is based on gender roles, social control, and patriarchy within the home. Often in a single parent home, these gender relations do play out in the same way and the same goes for same-sex parent home. The theoretical framework of the power-control theory gives insight on the issue of gender difference in delinquent behavior while considering the important implications of parental bonds (Hagan, Gillis, and Simpson, 1985, 1990, 1993; Hagan, Simpson and Gillis, 1987; McCarthy, Hagan and Woodward, 1999). Hagan's power-control was innovative in that the theory incorporated two concepts that are addressed in a variety of theories working to explain delinquent behavior,

Two concepts organize the classical theories of delinquency: power and control. The empirical distinction between these concepts is partly one of level of analysis. Power theories tend to be macrostructural and control theories microstructural, but they share a structural interest in relations of dominance. 
Power theories focus on relations of dominance that derive from control over the means of production; control theories focus on relations of dominance established within the family (1985:1154).

By using these two core concepts together Hagan and colleagues hoped to add to the understanding of the class differences and gender differences in rates of delinquency, ultimately relating gender to a "class" issue by speculating that women are, due to a sexist culture, in the lower class of modern society, thus males having more power and less control over them than females. Another key component of the power-control theory is dominance, Hagan asserts,

Relations of dominance emphasized in the power tradition, and defined in terms of class, are used to specify the conditions under which the genderdelinquency relationship rises and falls. Relations of dominance emphasized in the control tradition and explored in terms of the family are used to explain gender- delinquency relationships within specific classes (1985:1154).

The power-control says that within the family, parents reproduce the power relationships they act out in the workplace. Their respected occupational authority is then replicated in the home. Parent's class position, as defined through their work, influences the youth's involvement in delinquent behavior. According to Hagan, mothers are more responsible for the instruments of familial control thus; daughters are the objects of familial controls since mothers reproduce daughters in their own likeness (Hagan et al., 1985). Parents exert strong protective control over daughters on how they should act with an emphasis on cultural gender norms ( i.e."ladylike" behaviors) (Block 1984). Since mothers are the main agents of socialization, daughters are taught to fear punishment and social sanctions. Hagan explains that,

[A]dolescents, especially female adolescents, are taught to avoid risks generally and the risk of legal sanctions specifically. The testable implications 
of this part of a power- control theory of delinquency are that females will be deterred more by the threat of legal sanctions than males and that this effect will be produced more through maternal than paternal controls (1985:1156).

In a later paper discussing the power-control theory (1987), John Hagan writes that a family can be either identified as patriarchal or egalitarian, the patriarchal family structure is identified when a father acts in the traditional way of being the sole wage earner and a mother has only an unskilled job or does not work for pay. Hagan identified a single parent home as always being egalitarian, and while this is very interesting, testing single parent homes is beyond the scope of this thesis. There have been tests of the power-control theory interested in single parent homes and assessing the gender differences in delinquency (Mack and Leiber 2005). While that research contributes to the assertions of the theory about single-parent homes it does not look at how patriarchy identified through workplace authority affects daughters. The powercontrol theory, in its original form (1985), focused on two parent homes containing one father and one mother. A patriarchal family is defined by the low occupational authority of the mother and the high occupational authority of the father. In the patriarchal home the mother is viewed as the primary socialization agent and has been taught to reproduce daughters similar to her. Alternatively, sons are expected to reproduce their father's positions of authority which grants them more freedom than their female counterpart. Daughters are socialized to be like their mothers and are closely monitored so that delinquent behavior is unlikely; while sons are encouraged and permitted to take risks (Hagan, 1987). Hagan and colleagues view the egalitarian family as those families in which the father and mother experience comparable 
occupational authority. In this household type mothers and fathers experience similar levels of occupational authority and authority in the home. In the egalitarian family the treatment of sons and daughters is considered more or less equal in terms of socialization and control. Responsibility in child care is shared and female children do not receive the close supervision in the egalitarian or "balanced" family. Since female children are treated as equals to their male counterparts, risk taking and delinquent behavior is similar (Hagan 1987).

The power-control theory aims to explain why females are underrepresented in crime statistics by suggesting that they are "over-controlled" and thus less likely to engage in delinquent behaviors. Social control through parenting practices, connectedness to others, and control through social sanctions associated with culturally specific gender appropriate roles have a well developed place in theoretical and empirical work on delinquency. Sociological studies of mental health cite similar causes for the high levels of women with depression and internalizing disorders (Rosenfield 1999). Studies of mental illness are interested in why females are twotimes as likely as males to experience clinical levels of anger, depression, somatic, and suicide ideation problems (Vincent et al, 2008; Cauffman et al., 2007). Gender differences are the most consistent patterns in criminal behavior and mental health problems, and persist throughout the life course (Gore et al., 1993; Kessler 2000, 2003; Turner and Lloyd 1995). This thesis would like to add to a body of research that suggests the over-representation of females with depressive symptoms and underrepresentation of females in crime statistics is due to a common etiology. This 
thesis will use the power-control theory and test if family type (defined by the presence of a patriarchal family) is a common predictor of both delinquency and depressive symptoms for female's adolescences. Contemporary research shows that there is growing awareness and acceptance of the possibility of a common origin for delinquent behavior and mental illness (De Coster and Heimer 2001; Hagan et al., 2002; Rosenfield et al., 2005).

Delinquency and Mental Health: A Common Etiology

Through review of research that links delinquent behavior and mental health, two themes emerge: cultural specific gender roles and social control (Hagan and Foster 2003; Meadows 2007). Culturally specific gender roles which are enforced and created during childhood have been cited as causing the gender difference in rates of mental illness and delinquency (Hagan et al., 2002; Rosenfield et al., 1999, 2005). Social control can be either explicit as in parenting or implicit through bonds to others. Studies interested in the roles and actions associated with femininity and masculinity link outcomes of mental health and delinquency with child socialization practices that specify such roles and behaviors to children (Rosenfield 1999). Beginning in adolescence girls report higher levels of "internalizing disorders" like depression and anxiety and boys begin to engage in higher rates of "externalizing disorders" such as: anti-social behaviors or "delinquent" behaviors (Aarons et al. 2001; Garland et al. 2001; Kessler et al. 1994). Research suggests that the differing rates are due to females' tendency for interpersonal dependency and vulnerability to others' suffering as specified by "femininity" and bonds (Rosenfield et al. 2000; Turner and Turner 
1999; Kessler and McLeod 1984). Emotional closeness with parents is a strong predictor of females not engaging in delinquent behavior but the same cannot be said for males- suggesting differences in connectedness (Cernkovich and Giordano 1987; Gove and Crutchfield 1982; Van Voorhis et al., 1988). The relationship between adolescents and their parents plays an important role in the psychosocial adjustment of adolescents (Brody et al., 2003; Dorsey and Forehand 2003; Cernkovich and Giordano 1987; Gove and Crutchfield 1982; Van Voorhis et al., 1988).

The core themes stated above (gender roles and social control) are crucial when looking at the dominant discourse on a common etiology of mental health and delinquency. The power-control theory has been central to these studies since it includes both gender socialization and social control in its assertions which makes it ideal for this thesis. This thesis aims to add to the power-control theory by looking at how the theoretically important variables from the power-control theory address depressive symptoms for female adolescents. This research question is informed by the theoretical works of Sarah Rosenfield which are summarized in suggesting that females and males suffer from drastically different mental health disorders not due to the biological differences that are often cited but due to the social roles men and women must play out in order to fit into the gendered world.

$\underline{\text { Sarah Rosenfield's Work on Mental Health }}$

Rosenfield states that “...gender splits our experiences and understandings of the world and, in turn, the problems we suffer from and even the ways we suffer" (1999:210). Gender roles are primarily adopted through child socialization and 
maintained throughout life due to social forces which maintain gender stereotypes.

Analyzing a large body of empirical research Rosenfield develops a framework which suggests, “... sociocultural conceptions of masculinity and femininity- reflected in child socialization practices and adult social positions-differentially shape central dimensions of the self in males and females. These differences in dimensions of the self, in turn, predisposes males and females to opposite extremes of internalizing and externalizing disorders" (1999:210).

Rosenfield suggests that when considering all psychological disorders together there is no difference in rates of mental illness but males and females suffer from drastically different disorders. She writes,

"Females suffer more than males from internalizing disorders, including depression and anxiety, which turn problematic feelings inward against themselves. Women more often struggle with a sense of loss, hopelessness, and feelings of helplessness to improve their conditions. They endure attributions of self-blame and self-reproach. More often than men, women live with fears in the forms of panic attacks, and free-floating anxiety states" (1999:210)

Rosenfield asserts that conditions which create such gender differences in the types of mental disorders endured by males and females occur early on in the life course. Rosenfield suggests that child socialization practices, explicitly, and adult social positions shape the self in males and females. Rosenfield writes,

"Beginning in childhood, parents treat sons and daughters differently... Less control over sons encourages them to develop a risk-taking, entrepreneurial spirit that fits into the adult realm of productions. Greater instrumental control or supervision over daughters' activities discourages risk taking and independence in preparation for a primary emphasis on domesticity" (1999:212) 
Rosenfield goes on to say that these sexist cultural messages are presented through parenting practices and gives the example of parents giving females earlier curfews than males. She explains that parents treat sons and daughters differently to help them fit into the gendered roles of the adult world and because the parents themselves, internalize these sexist cultural values (Rosenfield 1999). This pattern is observable through a recent study (2001) of 1,618 youths, Garland and colleagues found that rates of ADHD and conduct disorder were significantly higher among males when compared to females, and rates of PTSD, separation anxiety, and major depressive disorders were significantly higher among females than males (Garland et al., 2001). Rosenfield would suggest that such findings indicate that the gender socialization which occurs in the early years of life may cause mental health outcomes in adolescence. In this study it is also obvious that males have the more "externalizing" disorders and alternatively females have higher rates of "internalizing disorder." Due to early childhood socialization young females are discouraged to act out and are pressured to fit into their gendered roles(Jordan,1997; Miller and Stiver 1997; Surrey 1991. Studies have found that in childhood males and females are equally as likely to be diagnosed with depression problems (Bimaher et al., 1996; Rutter 1986) but in adolescence females are significantly more likely to develop depression (Cohen et al., 1993). The high likelihood of females developing depression in early adolescence has been established as a result of increased levels of stress associated with school, peer groups, and their changing bodies (American Association of Women, 1991). 
Rosenfield suggests that daughters are "over-controlled" when compared to sons. The over control of daughters discourages risk taking behavior, independence and even induces fear in the young female. While females are "over-controlled" males receive less supervision and experience more freedom. These freedoms are felt by males through more confidence and assurance in their own agency (1999). Rosenfield gives an example of parent's "over-control" of females and writes, "parents may convince their daughters that the world is an unsafe place" (1999:215). Similarly it is suggest by the power-control that females in patriarchal family types are "overcontrolled" due to the power relations in the home. Alternatively, in the egalitarian home the treatment of sons and daughters is similar. The over-control of daughters suggests to them that they are frail, unable to fend for themselves, and thus must be dependent on others. Males receive cultural messages that value masculinity, independence, and control (Rosenfield 1999). Rosenfield says that this can be especially damaging since self-control and agency is valued in society. The powercontrol theory suggests that the over-control of daughters causes them to engage in less delinquent behavior and Rosenfield suggests that the over-control of daughter causes them to report higher rates of depression. This thesis suggests that since females from patriarchal homes receive most supervision when compared to females from egalitarian homes they will report more depressive symptoms and less delinquent behavior.

It is important to look at how control in the home affects depressive symptoms because of past publications which show that adolescents who have low levels of 
autonomy in the home report more internalizing disorders (Marsh et al., 2003). There are consequences of such socialization practices for females. Females tend to identify strongly with others and thus put others' needs before their own, which causes them to act less on their own behalf. The underlying premise of Rosenfield's work is that the high rates of depression (and other internalizing disorders like anxiety) for females are due to gender socialization received in childhood and the cultural messages received about femininity throughout the life course.

\section{Past Research on Mental Health and Delinquency}

Recent research has argued for the possible common etiology for criminal behavior and mental distress (Decoster and Heimer, 2001; Hagan et al., 2002; Rosenfield, 2005).Cultural messages received in childhood specifying gender appropriate roles and actions has shown implications on how individuals react to stress and the types of stress experienced throughout the lifetime. A study (2008) examining how sex differences in stress and stress-coping may interact in ways that contribute to differences in depression and delinquent behavior found that,

“...there were sex differences in the stress exposure and vulnerability that contributed to sex differences in well-being ... there were sex differences in coping styles... with girls reporting greater endorsement of an avoidant coping style and boys reporting greater endorsement of an action coping style...sex differences in stress and coping styles did not readily translate into differences in the conditioning effect of coping styles between stress and well-being...for girls, avoidant coping interacted with stress to amplify the negative of stress on depressive symptoms" (2008:131).

Girls are encouraged to avoid problems and confrontation and thus, to engage in avoidant or internal coping. Avoidant coping manifests itself through internal mental health disorders like depression and anxiety (DeCoster 2003)Females tend to respond 
to stress through avoidant coping, this is a reason for the disproportionate amount of women with depression and anxiety disorders (Kort-Butler 2008; Hagan and Foster 2003; DeCoster 2003). Alternatively, males tend to respond to stress through action coping, this finding speaks to the prevalence among males of externalizing disorders like alcoholism and conduct disorders (Kort-Butler 2008; Hagan and Foster, 2003, DeCoster 2003). Because of the stereotypical way reactions to stress are acted out by people, action coping or "delinquent behavior" has been considered mainly a "male" issue and research on females and delinquency is underrepresented and based on gender stereotypes and assumptions that only males can be delinquent (Girls Incorporated 1996).

As summarized above, according to Sarah Rosenfield (1999) mental health disorders vary in men and women due to gender socialization and the gendered nature of the social world not internal biological differences in males and females. Rosenfield states that “... social practices that are divided by gender produce both selves that are fragmented and mental health problems that are consistent with this fragmentation" (1999: 210). Thus, since the world is divided by gender and people often define themselves and activities in this gendered way, gender differences in living should be at the forefront on research looking at mental health. Wareham and Paquette Boots (2010) further highlight the significance of addressing gender in discourse on mental health and found that girls were approximately two times as likely as boys to have experienced clinical levels of anger/irritability, depression/ anxiety somatic, and suicide ideation problems. There were similar sex differences in 
psychopathology, with females reporting more mental health problems than males.

Similarly to the suggestions by Rosenfield this research has indicated that females do experience lower levels of control in their daily lives than males (Avison and McAlpine 1992; Mirowsky and Ross 1990; Umberson 1993).

When controlling for past law violation and depression, males report more exposure to stress associated with personal agency of criminal victimization and females report more exposure to communal stresses or stresses associated within the family (DeCoster 2003). As Rosenfield states, "Research on relational boundaries finds that females perceive themselves to be more dependent interpersonally and more emotionally reliant on others than males" (1999). This supports assertions by Rosenfield and highlights that females are prone to internalizing disorders partially due to their gender socialization which encourages them to identify with others and act less on their own behalf. Rosenfield warns of the consequences of the over control of females which cause them to act less on their own behalf,

"... the more individuals take on and attend to the feelings and desires of others, the less they can act in their own behalf. At the extreme, identifying strongly with others' interest precludes acting on one's own. The inability to act according to one's own interests also predisposes individuals to feelings of helplessness, and hopelessness, that characterize depressive reactions" (1999:216).

This is evident through national morbidity studies which show that females suffer from anxiety problems 2:1 when compared to their male counterparts and 50\% of cases start in adolescence (U.S. Department of Health and Human Services 1999).

Females are more prone to internalizing disorders due to their gender socialization which encourages them to identify with others and act less on their own 
behalf. Accordingly, research has shown that those who value social bonds to others are more likely to conform to conventional norms and engage in less delinquency, and those with weak bonds are more likely to deviate from norms and participate in delinquency (Booth et al., 2008). The body of research which suggests that bonds to others primarily explains rates of delinquency has also found complex results in the way males and females react to bonds to others. For example: females involvement in a sport team was positively associated with engaging in delinquency and the opposite was true for males (Booth et al., 2008). This finding indicates that males and females respond to connectedness differently and in ways not fully explained by only social bonds but perhaps how positive or "strong" those bonds are -as suggest by other research (Kerpelman and Smith-Adcock 2005). This complex relationship between gender and bonds to others needs to be addressed by research interested in the ways bonds to others encourages or discourages delinquent behavior.

Girls who report a more positive relationship with their mothers and are more autonomous are more likely to report high rates of self-esteem and are less likely to report having depressive symptoms and are less likely to have engaged in delinquency (Bynum and Kotchich 2006). Bynum and Kotchich's research also highlights the importance of a female to have feeling of autonomy in regards to mental health and delinquent behavior as suggested by Rosenfield. Rosenfield highlights the importance of autonomy in regards to mental health and suggests that the differences in rates or depression between males and females is due to females tending to report lower levels of autonomy (Rosenfield 1995). Research on adolescents (2004) found that parental 
effectiveness, as defined through a mother's attachment to her child/ren and close parenting style, is a major precondition for self-control in adolescents. This finding may be more complicated than suggested; Perrone and colleagues write,

"[A]lthough the parental efficacy-self-control link was quite robust our measures of race and family structure (along with sex and age) were significantly related to self-control...this analysis indicates the importance of family context, not simply patterns of parental monitoring and supervision, to the explanation of delinquency" (2004:307)

Perrone and colleagues go on to suggest that future research interested in looking at adolescent delinquency should look at self-control in conjunction with familyfunctioning and family context and they write that research that includes these variables will be "more likely to yield a complete understanding of the purported cause of crime and delinquency" (Perrone et al., 2004:307). They suggest that future research more specifically look at "family context." This thesis is interested in just that, and by using the power-control theory to address parental attachment and parental control as well as the presence of patriarchy in the family. Research has also asserted that for females the "mother-daughter" relationship is important in that "the mother-daughter relationship can provide a context in which the daughter's self-views are developed" (Kerpelman and Smith-Adcock 2005:193).

Through child socialization practices and adult social positions females receive cultural messages that emphasize dependency on others and discourage independence. Females are given earlier curfews than males and the less control of sons over daughters encourages males to develop risk taking behaviors to be independent. The over control of daughters discourages risk taking behavior and independence. Such 
cultural messages suggest to females that they are unable to fend for themselves and persist throughout the life course.

The power-control theory seems appropriate when looking at the gender difference in rates of mental health disorders and delinquency since it take into account child socialization based on the gender roles played out by the parents through patriarchy. The power-control theory suggest that in the patriarchal home the mother is viewed as the primary socialization agent and has been taught to reproduce daughters similar to her. Alternatively sons are expected to reproduce their father's positions of authority which grants them more freedom than their female counterpart. Daughters are alternatively socialized to be like their mothers, which prepares them for lives in domestic labor and consumption. Thus, sons are encouraged and permitted to take risks and daughters are closely monitored so that delinquent behavior is unlikely (Hagan 1987). The egalitarian family is a more balanced with the mother and father experiences similar levels of occupational authority and thus having similar parenting roles and socializing sons and daughters in the same way.

\section{$\underline{\text { Hypotheses }}$}

This thesis would like to have a discussion with the themes presented above and suggest that adolescent females who engage in delinquent behavior and those report having depressive symptoms may be simply reacting to certain social situations- and this thesis would like to highlight the social location of adolescence and how family type may either encourage or discourage delinquency or depression. Using the themes address above about the gender differences in child socialization, the 
power-control theory of delinquency and the theoretical work on mental illness by Rosenfield this thesis poses one question gives two hypotheses. The research question posed by this thesis is how does family type influence and adolescent female to engage in delinquent behaviors or report depressive symptoms. In this thesis it is hypothesized that females who have patriarchal family structures are less likely to engage in delinquent behavior than those with egalitarian family structures. As described above, using the theoretical notions of Sarah Rosenfield and the powerpontrol theory it is also hypothesized that females who have patriarchal family structures are more likely to have depressive symptoms than those with egalitarian family structures.

\section{Chapter 3: Methodology}

\section{$\underline{\text { Study Aims }}$}

Past research on mental health and delinquent behavior among youth has been limited by two problems which this research hopes to correct. First, a large portion of research interested in a common origin for mental illness and delinquent behavior has focused on these behaviors in either children (Kessler et al., 2009) or "at risk" populations (Loeber et al., 1998). This research will use a well respected and widely used data set that contains a large sample of adolescents, representative of the US population. Secondly, there has been limited research applying common theories of 
delinquency to females only. Because of the gender stereotypes "delinquent behavior" has been considered mainly a "male" issue and research on females and delinquency is underrepresented and based on assumptions that only males can be delinquent (Girls Incorporated 1996). This research also excludes males to control for the gender difference in the variables. This research uses the DSM (Diagnostic and Statistical Manual of Mental Disorders)- oriented scale of depression which offers a continuous measure of depression verses a dichotomous indicator, which likely results in more precise results, this is strength of this thesis which should be mentioned. The approach here is to apply the traditional power-control theory as it was developed by Hagan and colleagues and the theoretical assertions of Sarah Rosenfield to a sample of adolescent females.

\section{Description of the Data}

This research uses secondary data analysis to examine the effects of family type, parental control, and attitudes towards risk-taking behavior on delinquent behavior and depressive symptoms. All analyses will be performed on public-use data from the first wave of the National Longitudinal Study of Adolescent Health (Add Health). Add Health, a longitudinal study of nationally representative sample of adolescents in grades 7 through 12, is a school based study interested in health-related behaviors. According to Harris and colleagues (2009):

"Add Health is the largest, most comprehensive longitudinal survey of adolescents ever undertaken. Beginning with an in-school questionnaire administered to a nationally representative sample of students in grades 7-12, the study followed up with a series of in-home interviews conducted in 199495, 1996, 2001-02, and 2007-08. Other sources of data include questionnaires for parents, siblings, fellow students, and school administrators and interviews 
with romantic partners. Preexisting databases provide information about neighborhoods and communities" (cpc.unc.edu).

The present research analyzes the public-use data of the National Longitudinal Study of Adolescent Health, which is available on the Internet from the Interuniversity Consortium for Political and Social Research (1996) at the University of Michigan. The Public use dataset includes Wave I respondents and consists of a random sample of one-half of the core sample and one-half of the oversample of African-American adolescents. Wave I of interviews was conducted between April and December of 1995. Thus, for the wave to be used in this study (Wave I), 6,500 adolescents were interviewed in 1995 when they were 11 to 19 years of age, answering questions pertaining to the years 1994 to 1995 (Harris et al., 2009). The public use wave I data includes respondents answers from four sources: youth's inschool questionnaire, in-home interview, school administrators questionnaires, and parent questionnaire. This thesis uses youth respondents' answer from the in-school questionnaire and in-home interview.

The data used in this research is complicated in nature due to its sampling technique which ensured a representative sample. The primary sampling frame for Add Health is a database collected by Quality Education Data, Inc. Harris and colleagues write on the technique,

"Systematic sampling methods and implicit stratification ensure that the 80 high schools selected are representative of US schools with respect to region of country, urbanicity, size, type, and ethnicity. Eligible high schools included an 11th grade and enrolled more than 30 students. More than 70 percent of the originally sampled high schools participated. Each school that declined to participate was replaced by a school within the stratum" (2009). 
The data also includes several "special over-sampled" groups to ensure a large enough population for adequate analyses, these included: blacks from well-educated families, disabled adolescents, and sibling pairs for tests of genetics. "Incorporating systematic sampling methods and implicit stratification into the Add Health study design ensured this sample is representative of US schools with respect to region of country, urbanicity, school size, school type, and ethnicity" (Harries et al., 2009).

Measures of demographic information, levels of delinquent behavior and depressive symptoms, and family type information are from the adolescent in-school interviews drawn from Wave I. No scales used in the present research were present in the data and the final instruments for assessing delinquency, depression, risk-taking, and relational control were created for this thesis. Add Health used numerous sources to develop and construct the initial survey. Udry (2002) recommends using alpha reliability to validate scales created in research. This thesis used alpha reliability scores to indicate a strong scale. All scales used in present research were created using an additive approach or were developed using similar measures indentified in recent research assessing similar research outcomes.

\section{Dependent Measures}

The first dependent variable, Delinquent Behavior, is measured with a 14-item scale covering a variety of activities as reported in the past 12 months $(\alpha=.77)$. The primary focus for all information about respondent's engagement in delinquent behavior was on the past year or twelve month period. The activities include running away and property damage, minor delinquent behavior like shoplifting, and more 
serious forms delinquent behavior like selling drugs and fighting. The response categories range from zero (never) to three (five or more times). Individual items and Alpha coefficients are reported in Table 3.1 with the other index variables. The far left column identifies the alpha for the final variable used in this thesis and the middle column is the individual variables as they appeared in the data which combined make up the final measure as used in this thesis. The right column indicates the alpha score for each index addressed in this thesis. The delinquency measurement was used in previous research by Lisa Kort-Butler (2009). While this thesis differs in research question and frame from the work of Kort-Bulter, it gains validity when using measures used in past published research. This indicates that the measure is operationalized well since it has yielded significant results in past research. KortButler's work is interested in the gendered difference in how youth deal with stress and the gendered outcomes associated with stress, while this research is interested in exclusively female youth and how family type (the presence of patriarchy in the home) can predict delinquent behavior or depressive symptoms. This thesis also differs from Kort-Butler's study in core sample; while her research was not limited to females this thesis is only looking at females from two patent homes to obtain the results from the most traditional test of the power-control theory.

The second dependent variable in this study will be used to test the central aspect of Rosenfield's assertions that females from patriarchal homes and are less favorable of risk taking, and are more likely to report depressive symptoms. The primary focus for all information about respondent's depressive symptoms was based 
on the past week. Wave I of Add Health includes a modified version of the Center for Epidemiological Studies Scale (Radloff, 1977). Depressive symptoms in the present study is measured with a 14-item scale and included statements such as (During the past week) “you felt fearful," “you thought your life had been a failure,: “you didn’t feel like eating, your appetite was poor," and "you talked less than usual” $(\alpha=.73)$. The individual items can also be found in table 3.1. The response categories range from zero (never) to three (five or more times). This exact measurement was also used in research done by Kort-Butler (2009). As suggested earlier, while this thesis differs from Kort-Bulter, using measures from past publications adds to the validity of this thesis.

In sum, two dependent variables are used in this study to examine self-reported delinquent behavior and depressive symptoms. The first dependent variable measures any delinquent behavior in the past year, and the second measures the respondents self reported depressive symptoms for the past week. 
Table 3.1: Scale Items and Alpha Coefficients

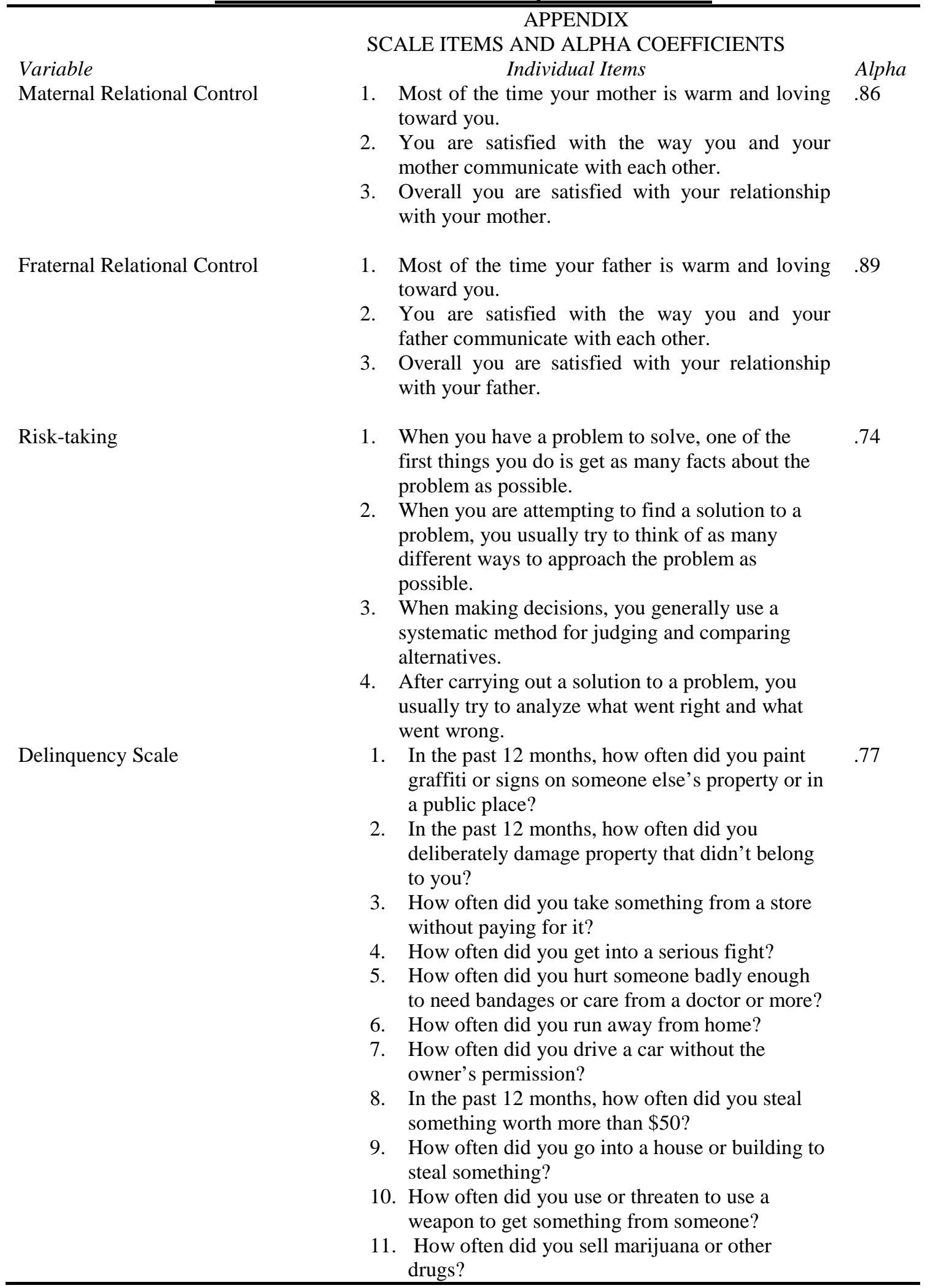




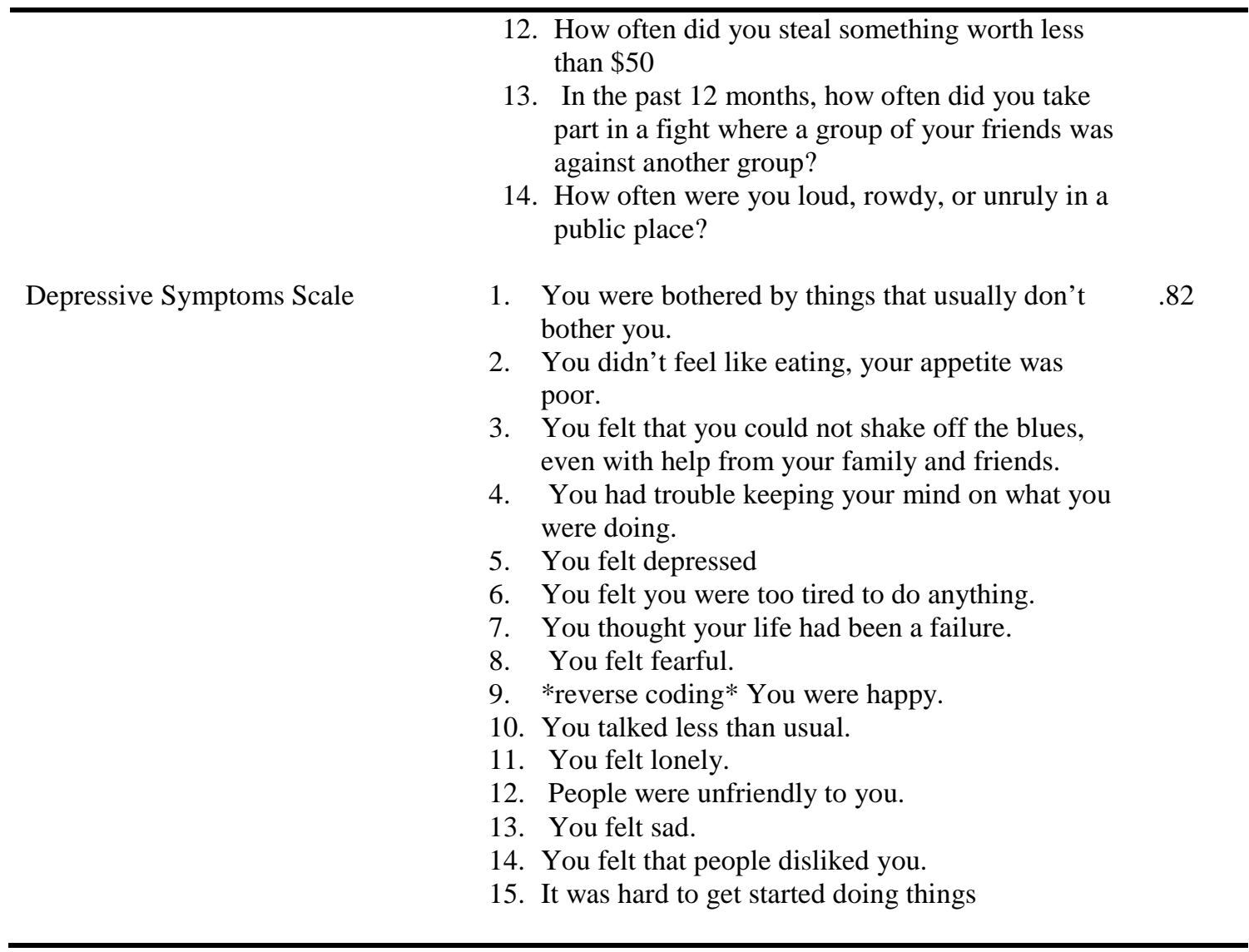

Independent Measures (see table 3.1)

The primary independent variables used in this study were the respondents' family type, control type variables (these asses the quality of relationship to parents and instrumental control), and youth's preference for risk-taking behavior. Although this research is primarily interested in testing the power-control theory and the theoretical assertions of Sarah Rosenfield, factors associated with class, parent's education, and race/ethnicity cannot overlooked due to the significant findings associated with these variables. Social class, race, and age were included as statistical controls, because of theoretical and empirical connections between social status and well-being as found and cited in chapter 2. 


\section{Family Type}

The independent variable of interest, family type, used the responses from two questions from the adolescent in-school questionnaire to adequately adhere to the specification of the power-control theory. A patriarchal family, as specified by Hagan and colleagues is defined by the low occupational authority of the mother and the high occupational authority of the father (1987). In a primary study focusing on a traditional test of the power-control theory, Andreas Hadjar, Dirk Baier, Klaus Boehnke, and John Hagan (2007) use the "Treiman scale of occupational authority" to determine family type. The "Treiman scale of occupational authority" is derived from international surveys on the prestige of many occupations. Treiman scores range from 18.1 (unskilled workers) to 78.9 (university lecturers and physicians).

In a first step, the Treiman-prestige score (Treiman, 1977) was used to convert the responses of parents to a question about their occupation into a "prestige score." To measure occupational authority difference between mothers and fathers in the workplace, a variable was generated from two other variables: type of paid work for each resident parent and labor force participation. Treiman scores of the professions of mother and father were then weighted with the score of the hours parents spent on the job. This was to take into account labor force participation as specified by the power control theory.

The process for creating the occupational prestige score for this research is duplicated from a study of the power-control theory (Hadjar et al., 2007). If a parent did not work outside the home, this parent's Treiman score was multiplied by 0 , if the 
parent worked part time (39 or less hours) his/her score was multiplied by 0.5 ; if a parent held a full time position (40 or more) her/his score was included in the analysis in full, i.e. multiplied by 1.0. The difference score was finally made into a dichotomous variable. Those with a higher prestige score of the father received a score of ' 1 ,' all others the score ' 0 .' Table 3.2 highlights the original categories from the add health data and those located in the second column from the right; with them are the occupational prestige scores associated with them. The far right column is the averaged group score used to create the final prestige score as identified by the method used in Hadjar and colleagues work (2007). The sample's weighted frequencies and percents are located in the left two columns.

Table 3.2: Parent's Occupational Prestige Score and Percents**

\begin{tabular}{|c|c|c|c|}
\hline Group Score & Individual Scores* & $\begin{array}{l}\text { Mother } \mathrm{N}=(1093) \\
\text { Mean }=33.9 \\
(27.47)\end{array}$ & $\begin{array}{l}\text { Father } N=(1093) \\
\text { Mean }=40.11 \\
(6.79)\end{array}$ \\
\hline 65.3 & & (3.13) & $(8.62)$ \\
\hline & $\begin{array}{l}\text { Doctor- } 50 \\
\text { Lawyer-72 } \\
\text { Scientist -74 }\end{array}$ & & \\
\hline 56 & $\begin{array}{l}\text { Teacher-60 } \\
\text { Librarian-54 } \\
\text { Nurse-54 }\end{array}$ & (22.96) & (6.34) \\
\hline 54.6 & $\begin{array}{l}\text { Technical-55 } \\
\text { Computer Specialist - } \\
51 \\
\text { Radiologist-58 }\end{array}$ & ( 2.78 ) & $(7.26)$ \\
\hline 52.5 & $\begin{array}{l}\text { Manager-53 } \\
\text { ExecutiveDirector-52 }\end{array}$ & $(5.38)$ & $(13.22)$ \\
\hline 45.25 & $\begin{array}{l}\text { Office worker-42 } \\
\text { Bookkeeper-49 } \\
\text { Office clerk-37 } \\
\text { Secretary-53 }\end{array}$ & (20.34) & (2.99) \\
\hline 40.3 & & $(5.22)$ & $(5.17)$ \\
\hline
\end{tabular}




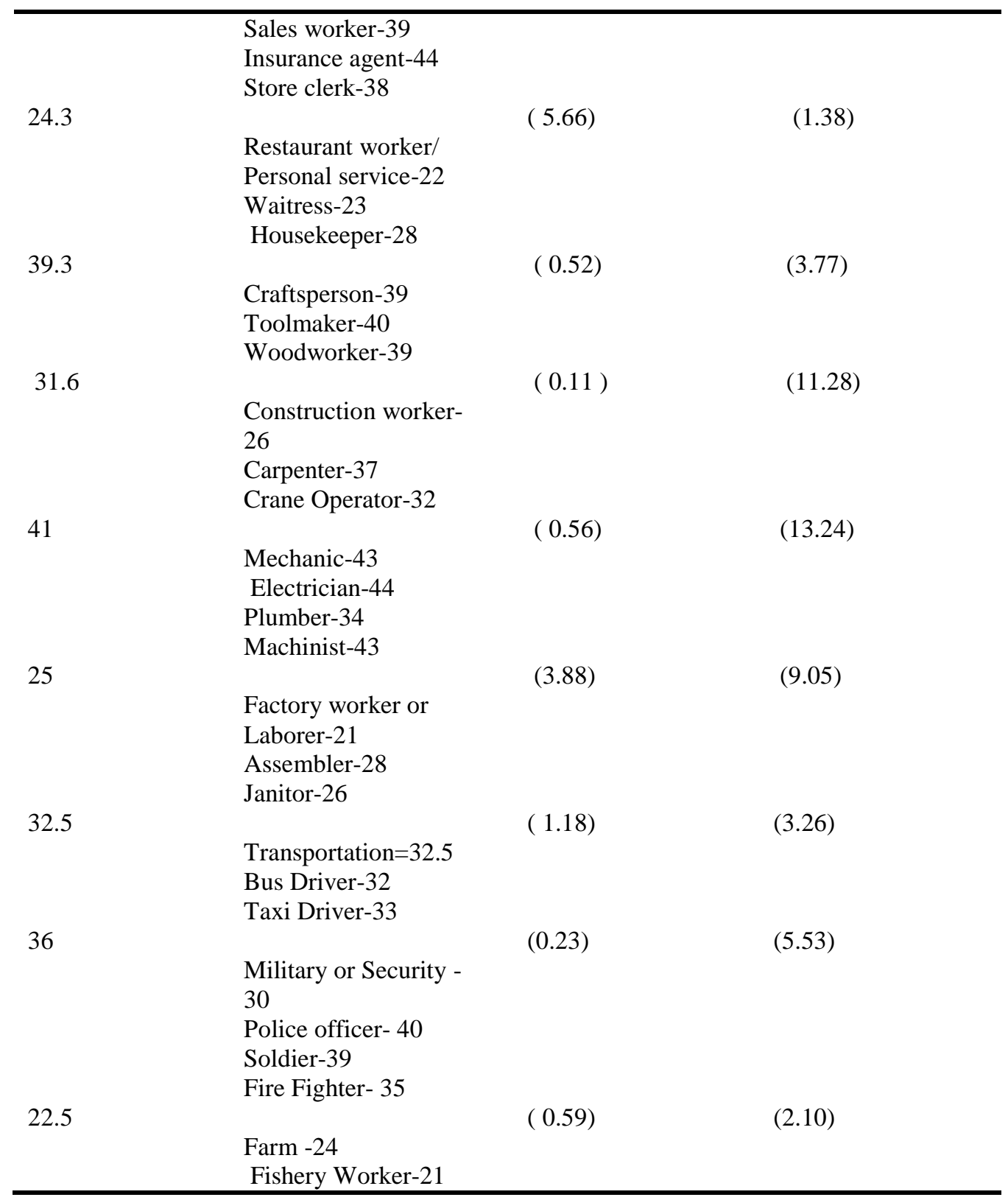

*Based on Treiman's Prestige scores, 1977**Percents presented in parenthesis 


\section{Instrumental and Relational Control}

Based on the power-control theory and prior research (Blackwell, 2000;

Hagan, Gillis et all., 1985; Hagan and Simpson et al., 1987, Mack \& Leiber, 2005) this research includes variables that capture quality or relationship with the mother and father and supervision. Maternal relational control and fraternal relational control is a scale that consists of responses to three items that assessed the level of attachment and closeness. Instrumental control is operationalized by a response to question that asks the youth whether the parents let the youth make her own decision about the time she has to be home on weekend nights. The relational and instrumental control variables approximate the measures used by Hagan and have been used in past published research testing the power-control theory (Mark \& Leiber 2005). The exact measures as specified in the original theory ask the respondent to "look back" to their youth and describe how their parents enacted control over them.

\section{Attitudes towards Risk Taking Behaviors}

Finally, an index was created to explore a central aspect of the power-control Theory and Rosenfield's primary theoretical assertion (Rosenfield 1999). Youth's attitudes toward risk taking was created using four questions that asked respondents about risk aversion were used for this variables and reverse coding was used. The data set used in this study does not have questions that directly ask youths about risk-taking as intended by the theory but questions assessing risk aversion are used instead. The theory specifies risk-taking behavior by asking the respondent if the statement "Things I like to do best are dangerous" is true (Hagan 1995). The measure used in this thesis 
was also used in research testing the similar aspects of the power-control theory (Mack \& Leiber, 2005).

\section{$\underline{\text { Controls }}$}

Following the method presented in Mack and Leiber (2005), this study includes traditional measures of social class. Several recent studies suggest that parent's education, especially the mother's, has a strong influence in a daughter's engagement in delinquent behavior and feelings of depression as well as age of first sexual encounter and likelihood to engage in illegal drug use (Durr et al., 2009). These variables are used to control for the suppressor effects education and class have on family type since education typically can predict occupational outcome. Mother's and father's education is measured by a single item indicator. This study used respondent's report of the highest education level attained by resident parents to create a fourcategory variable: less than high school; high school grad or GED; some college or trade school; college graduate or more.

Underclass Status is measured by responses to five questions about government aid. This variable is controlled for to account for the way in which patriarchy may differentially exist. For example patriarchy in the family is not exact and may be acted out in various way depending on income. For example a doctor and a mill worker would have very different homes, while both being considered patriarchal in this thesis. Age and grade of respondent will also be used as a control since all youths in the sample are considered adolescent. Age is centered at 11, the lowest reported age, and grade is centered at $7^{\text {th }}$, the lowest reported grade. These 
variables are centered at lowest value to increase the interpretability of the Beta coefficient, and to avoid multicoliniarity. This research uses information from the adolescent in school questionnaire to derive a self -reported race measure of race/ ethnicity. Race reflected the racial status of the adolescent respondent. Analysis is limited to those who only self reported a single race, those identifying as two were excluded. Exploring issues of race and ethnicity is beyond the scope of this thesis. Respondents were permitted to select more than one race. Past research has also show that race, class and age are predictors of both depression and delinquency in that both are more likely as age increases and in the case of delinquency it decreases as a respondent gets older. (Blackwell, 2000; Jensen, 1993; Simpson \& Ellis, 1995).

\section{$\underline{\text { Analysis Plan }}$}

To complete analysis, cases missing any Wave I variables were deleted. The present analysis includes respondents who participated in Wave I of Add Health. Respondents in the present analysis were limited to females $(3,356)$ who live with a resident "mother" including, adoptive mother, step-mother, and biological mother $(2,319)$ and a resident "father" including, adoptive father, step-father, and biological father $(1,850)$. To further filter the sample, thus creating the most ideal sample for the traditional test of the power-control theory (Hagan et al. 1985), the respondents whose household size was less than three were excluded, meaning that at the time of the interview they lived with a "mother" and a "father." Only those living in two parent homes including one "father" and one "mother" were included $(1,793)$ in order to complete a most traditional test of the power-control theory. This thesis acknowledges 
that this family type is declining in the United States, but maintains this as the final sample due to the specifications of the original power-control theory (1985). The final sample of respondents for regression analysis is limited to those with no missing variables $(1,093)$. The mean age was 14.9 years. The mean grade was 9.6. The racial/ethnic distribution of the sample was $66 \%$ white, $33 \%$ black or "other." The final sample is 1,093 respondents.

The data analysis program STATA was used to complete this research. Due to the nature of the sample, a survey analysis statistical software program such a STATA must be used to account for the complexity of the data highlighted earlier in the chapter. Unless accounted for, this sampling issue will give biased parameter estimated and incorrect variance estimates. Youths in the survey were selected for several analytical purposes which also cause the sample to be biased. While this data is complicated in the sampling technique, STATA is used to address these issues. STATA specifies using special survey data commands or "svy" commands to complete all analyses. "Svy" commands were used in this thesis. (Chantala \& Tabor, 1999, 2010)

The analysis was completed using OLS models as well as negative binomial logistic regression. A negative binomial regression model must be used on the analysis done with the dependent variable assessing delinquent behavior due to its skewed results. Negative binomial logistic regression is used to account for the skewed results and thus account for over dispersed variable. (See Table 3.3) In initial analysis the dependent variable, delinquency, was found to have a positive skew, thus negative 
binomial logistic regression models will be used (refer to Haynie et al. (2005) and Kort-Butler (2008) who also used this approached in their analysis of Add Health).

\section{Figure 3.1 Skewed results of Delinquency}

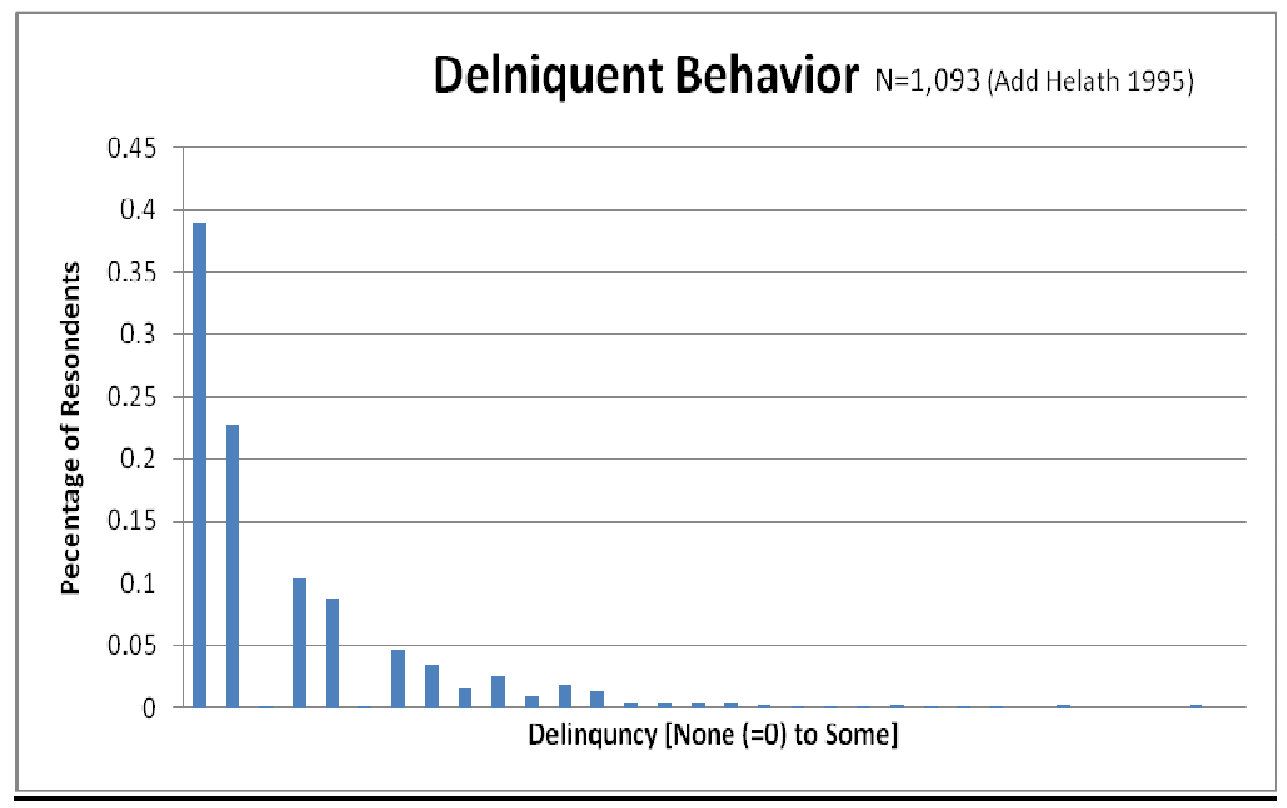

The variable was also over dispersed, with the standard deviation exceeding the mean. The skewed results of this variable may be due to the gendered nature of the delinquency index, since female behaviors are less likely to be delinquent in nature due to gender socialization (Rosenfield 1999, 2005). The depressive symptoms variable relied on ordinary least-squares regression and did not exhibit skewness or overdispersion. The primary concern of this research is determining if there is a difference in how family type influence outcome. To this extent the results are comparable. 
This thesis first presents descriptive statistics on the characteristics distributions of the independent variables. Next, Hypothesis 1- females from patriarchal homes will be less likely to report delinquent behavior- I explored using negative binomial logistic regression. This research fits four separate models. Model 1 estimates the crude relationship between household type and delinquent behavior. Past research suggest that race and age has a significant effect on the likelihood of engaging in delinquent behavior (Blackwell, 2000; Jensen, 1993; Simpson \& Ellis, 1995). In order to control for these influences, Model 2 controls for race, age, and grade. Model 3 incorporates variables that control for class. These variables act as suppressors on the family type variable since class may identify occupational prestige and also can influence a respondent's likelihood of engaging in delinquent behaviors since past research indicates class values play an important role in determining what behaviors are delinquent (Jensen, 1993). Model 4 incorporates variables of theoretical importance. The relational and instrumental control variables test the assertions made by the Power-control theory and accounts for a respondent's attitudes towards risk taking behaviors. All analyses were conducted in STATA 10.1 to correct for Add Health's complex survey design; sampling weights were applied to obtain population estimates.

OLS regression models are fit and depressive symptoms are regressed on family type to test hypothesis 2- that females from patriarchal homes are more likely to report depressive symptoms. The models follow the same approach as the regression on delinquent behavior. 


\section{Chapter 4: Findings}

\section{$\underline{\text { Descriptive Statistics }}$}

Table 4.1 shows the descriptive statistics for the independent and dependent measures used in this study. It is further explained in the methodology chapter, but this research is limited to females. $56.48 \%$ of girls are from patriarchal homes, indicating that the fathers in those homes have more occupational prestige associated with their positions. The frequencies reported in the table 4.1 are not integers due to the weights applied to the data because of the complex sampling technique as described in detail in chapter 3. Respondents reported having a closer relationship with their mother (measured by maternal relational control). The mean is 9.79 for mothers as compared to 9.38 for fathers. This is suggested by the power-control theory and Rosenfield also suggests that girls are more connected to mothers than fathers. The mean educational attainment between mothers and fathers (2.71 and 2.74) is high which explains the low percentage $(6.9 \%)$ of "underclass" individuals in the sample. This suggests that the final sample for the study includes a large proportion of those whose parents have graduated from high school and do not receive public assistance in any way. Only $6.9 \%$ of the final sample receive public assistant in any form. Descriptive statistics for a respondent's race is also provided in this table. Of the total number of females $(\mathrm{N}=$ 1,093) $72.8 \%$ are white. The descriptive statistics for both dependent measures are also provided. 
Table 4.1: Distributions of Weighted Variables and Descriptive Statistics $N=(1,093)$

\begin{tabular}{|c|c|c|c|c|c|c|}
\hline $\begin{array}{l}\text { Variable } \\
\text { Independent }\end{array}$ & Code & $\mathrm{N}$ & $\%$ & $\mathrm{M}$ & $\mathrm{SD}$ & Range \\
\hline$\overline{\text { Family Type }}$ & $\begin{array}{l}0=\text { Egalitarian } \\
1=\text { Patriarchal }\end{array}$ & $\begin{array}{l}475.67 \\
617.32\end{array}$ & $\begin{array}{l}43.52 \\
56.48\end{array}$ & & & \\
\hline $\begin{array}{l}\text { Maternal } \\
\text { Relational } \\
\text { Control }\end{array}$ & Low to high & & & 9.79 & 2.03 & $2.3-11.6$ \\
\hline $\begin{array}{l}\text { Fraternal } \\
\text { Relational } \\
\text { Control }\end{array}$ & Low to high & & & 9.38 & 2.22 & $2.3-11.6$ \\
\hline $\begin{array}{l}\text { Instrumental } \\
\text { Control }\end{array}$ & $\begin{array}{l}0=\text { no } \\
1=\text { yes }\end{array}$ & $\begin{array}{l}805.44 \\
287.56\end{array}$ & $\begin{array}{l}73.69 \\
26.31\end{array}$ & & & \\
\hline Risk Taking & Low to high & & & 3.74 & .63 & $1-5$ \\
\hline $\begin{array}{l}\text { Mother's } \\
\text { Education }\end{array}$ & Low to high & & & 2.71 & 1.06 & $0-4$ \\
\hline $\begin{array}{l}\text { Father's } \\
\text { Education }\end{array}$ & & & & 2.74 & 1.10 & $0-4$ \\
\hline Class & $\begin{array}{l}0=\text { Not } \\
\text { underclass } \\
1=\text { underclass }\end{array}$ & $\begin{array}{l}1016.49 \\
75.41\end{array}$ & $\begin{array}{l}93.0 \\
6.9\end{array}$ & & & \\
\hline Controls & & & & & & \\
\hline Race & $\begin{array}{l}1=\text { white } \\
0=\text { black/other }\end{array}$ & $\begin{array}{l}795.70 \\
296.20\end{array}$ & $\begin{array}{l}72.8 \\
27.1\end{array}$ & & & \\
\hline Age & Low to high & & & 14.81 & 1.76 & $11-19$ \\
\hline Grade & Low to high & & & 9.56 & 1.73 & $7-12$ \\
\hline Dependent & & & & & & \\
\hline Delinquency & $\begin{array}{l}0=\text { none } \\
1=\text { some }\end{array}$ & $\begin{array}{l}425.17 \\
666.73\end{array}$ & $\begin{array}{l}38.9 \\
61.0\end{array}$ & & & \\
\hline $\begin{array}{l}\text { Depressive } \\
\text { Symptoms }\end{array}$ & Low to high & & & .47 & .38 & $0-2.62$ \\
\hline
\end{tabular}

\section{Bivariate analysis}

Table 4.2 depicts the findings for a bivariate test of the power-control theory:

Those from patriarchal family types will be less likely to engage in delinquent

behaviors. The bivariate analyses addressed below are obtained from a slightly

different sample than the descriptive statistics. The bivariate analyses outlined below

do not use the sample weights and thus the $\mathrm{N}$ is slightly higher $(1,107$ compared to

1,093 with weights) due to not applying the weight. The weights adjust for oversampling of some demographic information like highly educated black families. The 
weights could not be used to obtain the cross tabulations. In STATA when using complex survey data, like Add Health, commands typically referred to as the "svy" commands are needed to further adjust for the complex design of survey data. The complex nature of the data was discussed in detail in chapter 3. "Svy" commands do not permit cross tabulations because the estimation cannot be calculated.

This hypothesis is partially supported: respondents who are from patriarchal homes were less likely $(58.7 \%)$ to engage in delinquent behaviors than those from egalitarian homes (62.6).

Table 4.2 Cross tabulation of Family Type and Delinquent Behavior (\%)

\begin{tabular}{llll}
\hline & No Delinquency & Some Delinquency & Totals \\
Egalitarian Family & $187(37.3)$ & $314(62.6)$ & 501 \\
Patriarchal Family & $250(41.2)$ & $356(58.7)$ & 606 \\
Total & 437 & 670 & 1,107 \\
\hline
\end{tabular}

$* * \mathrm{p}<.01$

Although the cross tabulation was not statistically significant, a multivariate analysis is needed to determine if family will become significant when other measures are controlled for. Also, this bivariate relationship does not included measures of quality of relationship with parents. Thus a multivariate test is needed to compare the effects of both the family type and the female's closeness to her parents which may influence how the family type affects the adolescent. Several variables were included in the final analysis due to the results of their bivariate relationship. Race is a significant predictor of delinquency in bivariate tests. (See table 4.3) 
Table 4.3 Cross tabulation of Race and Delinquent Behavior** (\%)

\begin{tabular}{llll}
\hline & No Delinquency & Some Delinquency & Totals \\
White & $309(42.7)$ & $414(57.2)$ & 723 \\
Black/Other & $128(33.3)$ & $256(66.6)$ & 384 \\
Total & 437 & 670 & 1,107 \\
\hline
\end{tabular}

$* * \mathrm{p}<.01$

A cross tab shows (table 4.4) that black/other homes are less patriarchal (49.4) in this sample when compared to white (56.9) and this relationship is significant as the predicted probability is .04 .

Table: 4.4 Crosstab of Race and Family Type * $(\%)$

\begin{tabular}{llll}
\hline & Egalitarian & Patriarchal & Totals \\
White & $311(43.0)$ & $412(56.9)$ & 723 \\
Black/Other & $190(49.4)$ & $194(50.5)$ & 384 \\
Total & 501 & 606 & 1,107 \\
\hline
\end{tabular}

*p $<.05$

$\underline{\text { Analyses }}$

This research first examines the power-control theory. Negative binomial logistic is used for this test due to the skewed results of the dependent variable which is discussed in detail in chapter 3. The skewed variable was transformed to be dichotomous and responses are dichotomous; either "no delinquent behavior" or "some delinquent behavior"- the most appropriate method is the negative binomial logistic regression due to the skewed results and since the variable is dichotomous 
between "none" and "some." The separate models used to regress delinquent behavior on the relevant variables was informed by the assertions of the power control theory, starting with the most basic test then including variables that are predictors of delinquency. Then to illuminate the assertions of Sarah Rosenfield, depressive symptoms are regressed on the independent variables. This thesis first tests the most basic form of the power-control theory then in the second model adds controls for race, age, and grade. Then the third model controls for social class differences. The fourth model adds variables assessing control within the home as specified by Hagan (1985).

\section{$\underline{\text { Multivariate Analyses }}$}

To test hypothesis 1 , delinquent behavior is regressed on family type, with egalitarian family type serving as the reference category (Table 4.5, Model 1). The foundation hypothesis of the power-control theory is examined and in this particular test of the power-control theory family type, as identified in this research, is not a significant predictor of delinquency for adolescent females. In model 2 , delinquent behavior is regressed on age, grade, and family type and this model also controls for race. Race is a significant predictor of a respondent reporting engagement in delinquent behavior- those who reported their race as "white" are less likely to engage in the types of delinquency used in this research.

Model 3 adjusts for the parent's education and social class. These independent variables are used to adjust for the differences in which patriarchy is enacted within the family. Race remains significant in model 3, but the coefficient decreases slightly 
when controlling for class and parents education. Model 4 examines whether there is a significant relationship for the effect of patriarchal home when adjusting for instrumental control, (parents picking curfew time) relational control, (quality of relationship with parents) and attitudes toward risk taking behavior. The effect of patriarchal family type continues to be non-significant when controlling for those theoretically relevant variables.

The maternal relational control variable is significant to the .001 level suggesting a very strong negative relationship between a respondent's relationship with her mother and her likelihood of engaging in delinquent behaviors. The coefficient of attitudes toward risk taking is significant (Table 4.6, Model 4) but, this finding contradicts the power-control theory which asserts that those with higher tastes for risk taking are more likely to engage in minor delinquent behavior. The findings from the regression indicate the opposite and that as attitudes towards risk taking increase the likelihood of engaging in delinquent behavior decreases. To clarify this relationship I tested it with a bivariate analysis. The coefficient was (-.190) and the standard error term is (.037). This relationship was significant to the .001 level. The relationship still contradicts the theory. There are possible reasons for this: this could be an incorrect measure due to inappropriate data used to test theory or this opposing relationship may be due to the fact that females who have more tastes for risk taking are less likely to engage in delinquent behavior because they perceive a stronger sense of repercussion. Since females whose race was coded as "black/ other" were more likely to engage in delinquency, the bivariate relationship between race and 
delinquency was examined and while a respondents race being coded as black/other did indicate a positive relationship with attitudes towards risk taking (the coefficient $=$ .019) the finding was not statistically significant. The relationship between attitudes towards risk and delinquency will be further addressed later in chapter 5 of this thesis.

Hypothesis 2 was tested using OLS regression models. To test hypothesis 2: females from patriarchal homes are more likely to report depressive symptoms, depressive symptoms is regressed on the assertions of the power-control. The dependent variable assessing depressive symptoms is regressed on family type, with egalitarian family serving as the reference category (Table 4.6 Model 1). Patriarchal family type has no significant effect on the dependent variable. This finding does not support hypothesis 2 . The second model adds controls for race, age, and grade. Race is significant, in that those respondents who reported their race as white were less likely to report suffering from depressive symptoms. Model 3 adjusts for parent's education and social class. In model 3, race is non-significant when controls for social class are included. Mother's education has a significant negative effect on depressive symptoms. Since model 3 controls for class, the relationship between mother's education and respondent reporting depressive symptoms is significant in that as a mother's education increases the likelihood of a daughter reporting depressive symptoms decreases.

Model 4 tests whether there is a significant relationship for the effect of patriarchal family type on depressive symptoms when adjusting for instrumental control (curfew time), relational control (quality of relationship with parents) and the 
respondent's attitudes toward risk taking behavior (Table 4.6, Model 4). Maternal relational control and fraternal relational control is significant and suggests that girls who have a good relationship with their mother and father are less likely to be depressed. Instrumental control is not significant. The bivariate relationship was then addressed, since one main assertion of Rosenfield is that girls who have more direct control over them in the home will be more depressed. The relationship is positive in that, girls who have parents who chose their curfew do report more depressive symptoms, but the relationship is not statistically significant. In model 4 the variable assessing attitudes towards risk taking behaviors is examined, and supports the assertions suggested by Rosenfield- that those with higher tastes for risk taking are less likely to suffer from depressive symptoms.

In this last model race and mother's education are no longer significant. The last model has the largest R2, this suggest that model 4 predicts slightly over $19 \%$ of the variance in depression. The second hypothesis that females from patriarchal family structures are more likely to suffer from depressive symptoms is not supported by the data. This relationship is surprising, but it is possible that the depression suggestion by Rosenfield is not noted until later in the life course. The gender socialization process, which she suggests causes depression, might still be in the formative stages during adolescence. This finding will be discussed further in chapter 5. Mother's education became non-significant in the final model indicating that a respondent reporting depressive symptom is better explained by maternal and fraternal relational control as well as the respondent's attitudes towards risk taking behaviors. 


\section{$\underline{\text { Significant Findings }}$}

The measure used to assess family type in this research provided no significant findings but this does not mean we should use this as a reason to throw away the power-control theory. This finding suggests that further information is needed to assess patriarchy in the home, as job categories and the gendered makeup of the workplace has changed since the onset of the power-control theory, in the early 1980s. Race was included in this research to control for different forms of patriarchy and the finding show that those respondents who reported their race as black or other were more likely to engage in delinquent behavior and more likely to report having depressive symptoms. This finding suggests that there may be cultural difference in gender norms and expectations. Race was also found to be a significant predictor of depression in this thesis. But most importantly it should be noted that when controlling for class variables race became non-significant for predicting depressive symptoms. These findings will be discussed in detail in chapter 5 .

The negative relationship between maternal relational control and delinquency and depression is consistent with theoretical assertions made by the power-control theory. The relationship between mothers and daughters is has great implications for future research. This was consistent for father-daughter relationships but it was less significant. As the descriptive statistics indicated, and the power-control theory suggests (mean is 9.79 for mothers compared to 9.38 for fathers), daughters typically have stronger relationships with their mothers. Attitudes towards risk-taking behavior indicated significant finding for both dependent variables. As suggested by Sarah 
Rosenfield, females with higher tastes for risk were less likely to report depressive symptoms, suggesting that the over control of females may account for those feelings of helplessness. The inverse relationship between attitudes towards risk-taking and delinquency suggests two things. First,females may be engaging in different forms of delinquency not covered in the index. Secondly, the measure which asses a female's attitudes towards risk-taking in this research needs to be reworked to assess for different types of risk.

In sum, these findings indicate that the mother-daughter relationship and race relations contribute to disparities in depression and differences in delinquent behavior for adolescent females. The mother-daughter relationship has implications for both delinquency and depression. When the relationship is strong it decreases the likelihood of both. Race is significant in predicting delinquent behavior, and as the crosstab shows those minority homes are less likely to be patriarchal. This suggests that the cultural definitions of femininity are not constant in all family types and may vary based on race thus the treatment of girls in non-white homes may be more similar to those from egalitarian homes regardless of parents' occupation. Race became nonsignificant in analysis on depressive symptoms after controlling for social class indicators; indicating that the relationship between depression and race is partially explained by social class. These findings will be discussed in detail in chapter 5 . 
Table 4.5: Negative Binomial Logistic Regression on Delinquency

\begin{tabular}{|c|c|c|c|c|}
\hline & Model 1 & Model 2 & Model 3 & Model 4 \\
\hline Patriarchal Family Type & $\begin{array}{l}-.011 \\
(.057)\end{array}$ & $\begin{array}{l}-.006 \\
(.056)\end{array}$ & $\begin{array}{l}.013 \\
(.058)\end{array}$ & $\begin{array}{l}.012 \\
(.058)\end{array}$ \\
\hline Maternal Relational Control & & & & $\begin{array}{c}-.044 * * * \\
(.012)\end{array}$ \\
\hline Fraternal Relational Control & & & & $\begin{array}{l}.030^{* * *} \\
(.011)\end{array}$ \\
\hline Instrumental Control & & & & $\begin{array}{l}-.095 \\
(.064)\end{array}$ \\
\hline $\begin{array}{l}\text { Attitudes Toward Risk } \\
\text { Taking(High=More) }\end{array}$ & & & & $\begin{array}{c}-.139 * * * \\
(.038)\end{array}$ \\
\hline Under-class & & & $\begin{array}{l}.052 \\
(.105)\end{array}$ & $\begin{array}{l}.070 \\
(.088)\end{array}$ \\
\hline Mother's Education & & & $\begin{array}{l}-.022 \\
(.031)\end{array}$ & $\begin{array}{l}-.009 \\
(.030)\end{array}$ \\
\hline Father's Education & & & $\begin{array}{c}.003 \\
(.027)\end{array}$ & $\begin{array}{l}.008 \\
(.027)\end{array}$ \\
\hline Black/other & & $\begin{array}{c}.186^{* * * *} \\
(054)\end{array}$ & $\begin{array}{c}.178 * * * \\
(.048)\end{array}$ & $\begin{array}{l}.149^{* *} \\
(.047)\end{array}$ \\
\hline Age & & $\begin{array}{c}.080 \\
(.054)\end{array}$ & $\begin{array}{c}.072 \\
(.056)\end{array}$ & $\begin{array}{l}.061 \\
(.055)\end{array}$ \\
\hline Grade & & $\begin{array}{l}-.110 \\
(.057)\end{array}$ & $\begin{array}{l}-.101 \\
(.059)\end{array}$ & $\begin{array}{l}-.096 \\
(.057)\end{array}$ \\
\hline Constant & $\begin{array}{c}-.486 * * * \\
(.040)\end{array}$ & $\begin{array}{l}-.684^{*} \\
(.322)\end{array}$ & $\begin{array}{l}-.593 \\
(.352)\end{array}$ & $\begin{array}{c}.741 \\
(.441)\end{array}$ \\
\hline$F=$ & .04 & 5.10 & 3.19 & 6.20 \\
\hline
\end{tabular}

$\mathrm{p}<.001$ ***, $\mathrm{p}<. .10^{* *}, \mathrm{p}<.050^{*}$ Note: Unstandardized coefficients with standard errors in parentheses 
Table 4.6: OLS Regression on Depression

\begin{tabular}{|c|c|c|c|c|}
\hline & Model 1 & Model 2 & Model 3 & Model 4 \\
\hline Patriarchal Family Type & $\begin{array}{l}.044 \\
(.024)\end{array}$ & $\begin{array}{l}.041 \\
(.023)\end{array}$ & $\begin{array}{l}-.047 \\
(.023)\end{array}$ & $\begin{array}{l}.042 \\
(.022)\end{array}$ \\
\hline Maternal Relational Control & & & & $\begin{array}{c}-.042 * * * \\
(.009)\end{array}$ \\
\hline Fraternal Relational Control & & & & $\begin{array}{c}-.034 * * * \\
(.006)\end{array}$ \\
\hline Instrumental Control & & & & $\begin{array}{c}.021 \\
(.026)\end{array}$ \\
\hline Attitudes Toward Risk & & & & $-.060 * *$ \\
\hline Taking(High=More) & & & & $(.023)$ \\
\hline Under-class & & & $\begin{array}{l}.086 \\
(.064)\end{array}$ & $\begin{array}{l}.102 \\
(.061)\end{array}$ \\
\hline Mother's Education & & & $\begin{array}{l}-.026^{*} \\
(-.013)\end{array}$ & $\begin{array}{l}-.015 \\
(.012)\end{array}$ \\
\hline Father's Education & & & $\begin{array}{l}-.013 \\
(.012)\end{array}$ & $\begin{array}{l}-.012 \\
(.011)\end{array}$ \\
\hline Black/other & & $\begin{array}{l}.069 * \\
(.028)\end{array}$ & $\begin{array}{c}.054 \\
(.028)\end{array}$ & $\begin{array}{l}.025 \\
(.026)\end{array}$ \\
\hline Age & & $\begin{array}{l}.047 \\
(.023)\end{array}$ & $\begin{array}{l}.030 \\
(.024)\end{array}$ & $\begin{array}{l}.020 \\
(.022)\end{array}$ \\
\hline Grade & & $\begin{array}{l}-.022 \\
(.023)\end{array}$ & $\begin{array}{l}-.004 \\
(.024)\end{array}$ & $\begin{array}{l}-.008 \\
(.022)\end{array}$ \\
\hline Constant & $\begin{array}{c}.495^{* * * *} \\
(.020)\end{array}$ & $\begin{array}{l}-.018 \\
(.155)\end{array}$ & $\begin{array}{l}.170 \\
(.169)\end{array}$ & $\begin{array}{c}1.30^{* * * *} \\
(.210)\end{array}$ \\
\hline $\begin{array}{c}\mathrm{R} 2 \\
\mathrm{~N}=1,093\end{array}$ & .003 & .026 & .041 & .192 \\
\hline
\end{tabular}

$\mathrm{p}<.001^{* * * *}, \mathrm{p}<. .10^{* *}, \mathrm{p}<.050^{*}$ Note: Unstandardized coefficients with standard errors in parentheses 


\section{Chapter 5: Discussion and Conclusion}

\section{$\underline{\text { Discussion }}$}

I began this thesis with the perspective that family type would predict outcomes of delinquent behavior and depressive symptoms. This research argued that those females from patriarchal homes would be less likely to report engaging in delinquent behavior and more likely to report depressive symptoms. The first part of the argument made in this thesis was a traditional test of the power-control theory with a sample limited to female respondents-which is unique to this research and as past research asserts, will control for gender differences in the variables. The second part of the argument was added by me in order to test a possible common etiology for delinquency and mental illness. To do this I used the work of Sarah Rosenfield to add to the power-control theory by testing if family type (i.e. the presence of patriarchy in the home) could predict a female adolescent's depressive symptoms. This addition to the power-control theory was based on theoretical notions presented by Rosenfield (1999, 2006).

While the hypotheses yielded no significant results and thus reveals several problems with the variable assessing family type as well as a possible critique of the power-control theory which will be addressed later in this chapter, this research has several significant findings and has many implications for future research. In the present research I showed that as predicted by the power-control theory those females who reported having high levels of relational control through good relationships with 
their mother and father were less likely to engage in delinquent behavior. This is consistent with past findings on female delinquents and supports assertions which suggest that females are less likely to be delinquent when bonds to others are strong (Bynum \& Kotchich, 2006; Hirschfield et al., 1976; Kerpelman \& Smith-Adcock, 2005; Turner, 1996). While race was not important theoretically for this thesis it yielded significant results. The race variable was included to control for the various way patriarchy can be enacted in home due to cultural differences in masculinity and because it was significant in bivariate analyses. If a respondent race was coded as "black" or "other" they were significantly more likely to report engaging in delinquent behavior. This variable decreases in significance once measures of social class are included; this suggests two things. First, the types of delinquent behavior addressed in this research are more typical of a disadvantaged population due to cultural differences (Anderson 1990, 1999). Secondly, it is also possible that the finding suggests that those who report their race as "white" are engaging in different types of delinquency or due to cultural specific messages about white femininity are engaging in delinquent behaviors less often. The bivariate relationship suggests this since race is a significant predictor of delinquency but social class is not. So, it is more likely that there are racial differences in ideas about femininity that create theses differences.

While the power-control theory asserts that those with higher tastes for risk will be more likely to engage in delinquent behavior, this research finds the opposite relationship in that those females with higher tastes for were less likely to engage in delinquent behavior. The index variable used to measure risk-taking behavior has been 
used in a past study (Mack \& Leiber, 2005) of the power-control theory using Add Health data (Mack \& Leiber, 2005). That particular study did yield significant results in support of the power-control theory's assertions on risk taking behavior. There are three possible explanations for the differing findings between Mack and Leiber's study and this thesis. First, in Mack and Leiber's study, from which the measure for this research is borrowed, the findings indicate that risk taking is only a significant predictor of delinquency for males and only for females from under-class families. Thus, the findings would be different since, as stated in the methodology chapter, the sample used in this research contains a very small percentage $(6.9 \%)$ of underclass respondents. This sampling issue may help in explaining the inverse relationship of this measure. Secondly, this research was a traditional test of the power-control theory and thus the sample was limited to females from two-parent homes (one "mother" and one "father"). In the Mack and Leiber's study the sample was composed of respondents from single mother homes and this distinction indicates another difference in the sample and suggests that those adolescents from single-mother homes may experience and act out risk-taking in an alternative way which is more addressed by the measure used in this thesis. Lastly, another possible explanation may be that adolescents from two-parent homes as opposed to those in single mother homes, which is the case in Mack and Leiber's study, feel more control over them since they have two parents in their home. The adolescents from two parent homes may consider risk taking behaviors but then are less likely to actually act out in delinquent ways. 
Depression yielded significant results when regressed on relational control. This finding is not surprising and is consistent with current literature on mental health and females which has found that females perceive themselves to be more dependent on others and value the well being of family members as very important for mental health of adolescent females (Barnett \&Gotlib, 1988; Hirshfieldet al., 1977; Kessler \& McLeod, 1984; Turner, 1996). Race was most significant in predicting depressive symptoms when class is not controlled for, this partially suggests that those who are from a socioeconomically disadvantaged home are more likely to suffer in both externalizing and internalizing disorders due to the increased stressors associated with being low-income. But, as stated elsewhere in this thesis, the sample used in this study contains a very small percentage of low-income adolescents. This suggests that while class may explain some of the findings it is more likely that the difference outcomes for race and delinquency and depression for female adolescents is more appropriately explained by cultural difference in ideas about femininity.

Mother's education was significantly negative, in that, the more educated a respondent's mother was, there was a decrease in the likelihood of her daughter reporting depressive symptoms. The significantly negative relationship between mother's education and adolescent depression then suggests that those mothers with high levels education may be more likely to know the benefits of a good motherdaughter relationship or are less stressed at low income jobs and have more time to spend with their children. When maternal relational control is included in the analysis mother's education becomes non-significant. It should be noted that in supplementary 
analyses, the family type variable was also created with education serving as the "occupational prestige" measure. Meaning in place of parents occupational prestige score, years of education was used and all analyses were preformed. This yielded no significant results and thus to be consistent with the original power-control theory, and because years of education doesn't always translate into occupation, the Treiman prestige scores were used in final analysis.

Rosenfield's work asserts that those with higher tastes for risk will be less likely to report depressive symptoms. Rosenfield suggests that in parenting, less control of sons over daughters encourages males to develop risk taking behaviors and that parents treat sons and daughters differently to help them fit into the gendered roles of the adult world (Rosenfield 1999). The over control of daughters discourages risk taking behavior and independence. This can be particularly damaging since selfagency is valued in society. These consequences can be seen as higher rates of depression for women (Rosenfield, 1999). While controlling for all theoretically important variables, relational control, and instrumental control this thesis showed that those females who had higher tastes for risk were also less likely to report depressive symptoms. A willingness to take risks has been linked to higher levels of independence (Hagan, 1981). Depression is linked to a low perceived control and less independence (Mirowsky \& Ross, 1990). This finding is instrumental in adding to work done by Rosenfield which suggests that the traditional female role and values associated with femininity are harmful to female's wellbeing (1995). Other research has found that males feel more in control in both behavior and perception and females 
have lower self-esteem and less feelings of control in adolescence (Joseph et al., 1992;

Owens, 1994).

\section{$\underline{\text { Strengths }}$}

This thesis has several strengths which contribute to the significance of the findings. The measured are valid and have been used in past publications (Kort-Butler, 2009; Mack \& Leiber, 2005). This research is interested in a common theory of delinquency that involves females. This is very important, since most theories of delinquency were developed for males and tend to study delinquency through empirically looking at males. By limiting the analysis to females only, this thesis also contributes to the limited amount of research on females lives. This research adds to a growing body of literature which indicates that parents' emotional closeness to their daughters is a powerful predictor of delinquency (Cernkovick \&Giordano, 1987; Van Voorhis, et al., 1988). This research is also important since it looks at the possible intersections of delinquency and depression together for adolescent females, which has implications for the epidemiology of mental health and studies of the life course.

\section{$\underline{\text { Limitations }}$}

The first hypothesis that females from patriarchal homes will be more likely to engage in risk taking behaviors than females from egalitarian homes was not supported by the data. This does not mean that the power-control theory should not be considered for explaining female delinquency in the future. The current findings regarding the significance of family type and patriarchy in the home deserves further consideration as there are a limited number of studies which test this theory on only 
females. The second hypothesis that females from patriarchal family structures are more likely to suffer from depressive symptoms is also not directly supported by the data. This does not mean that future tests using the power-control theory to look at depression or other mental illnesses should not be done, but again, more accurate measures of family type may yield more significant findings when looking at the bivariate relationship between family and depression. The dependent variables are also less comparable since delinquency was measured in the past year, and depression was measured in the past week.

This non-significant finding may be due to three possible issues. First, the variables used to create the measure for family type are not directly associated with actual or perceived patriarchy in the home and thus rely on broad job categories and assumptions about those job categories. The method used to create the family-type variable has been used in a past study of the power-control theory by Hagan himself (1987) but that study had more specific information on the parent's occupation and the data used in this research had only a few broad job categories. It is also possible that the Treiman prestige scores are dated since the most recent addition to the book was made in 1977, eighteen years before the Add Health data set was created. For example, there has been a huge increase in jobs related to computers and in the tech field since 1977 and less US jobs which involve factory working. Secondly, identifying the presence of patriarchy in home is very complicated as patriarchy can be constructed and performed in various ways and typical studies of the power-control theory require the respondent to reflect back to childhood to identify the family type. 
Ideal questions for future tests of the power-control theory should ask a respondent about perceived patriarchy in the home. There are also issues with using crosssectional data and the power-control theory. For example, a respondent may have just moved in with their father at the time of the survey. This would then not provide an accurate look at how patriarchy works in the home, if only a few weeks prior the respondent was living with a single mother.

While these are problems identified with the variables used in this thesis these limitations are not large enough to deem this research invaluable. The issues with addressing patriarchy in the home highlight the difficulty in measuring patriarchy with occupational prestige. Future research interested assessing patriarchy in the home should be aware of the complicated nature of patriarchy. This research also addresses the fact that a limited percentage of females are engaging in the types of delinquency addressed by the index used in this thesis and future research should be aware of the possibility that females are engaging in different types of delinquent behaviors.

\section{$\underline{\text { Future research }}$}

There are many implication suggested from the findings in this thesis for future research. Future research will benefit from looking at adolescents degree of empathy. Past research suggests that individuals who identify strongly with others' feelings are more likely to become depressed and those who identify little with other's feelings are at risk for aggressive or anti-social behaviors (Rosenfield et al., 2000). Thus it would be interesting for future research to test whether family type can predict levels of empathy. Future research should also test the possibility that differences in 
delinquency may be caused by differences in attachment, since delinquency does affect connectedness to parents. In a bivariate tests (Table 5.1) regressing maternal relational control and fraternal relational control on delinquent behavior, delinquent behavior was significantly negative in predicting quality of that relationship. This should be further studied with a path analysis to discover if delinquency causes the poor relationship or if the poor relationship causes the delinquency. 


\section{Table 5.1: OLS Delinquency regressed on Relational Control}

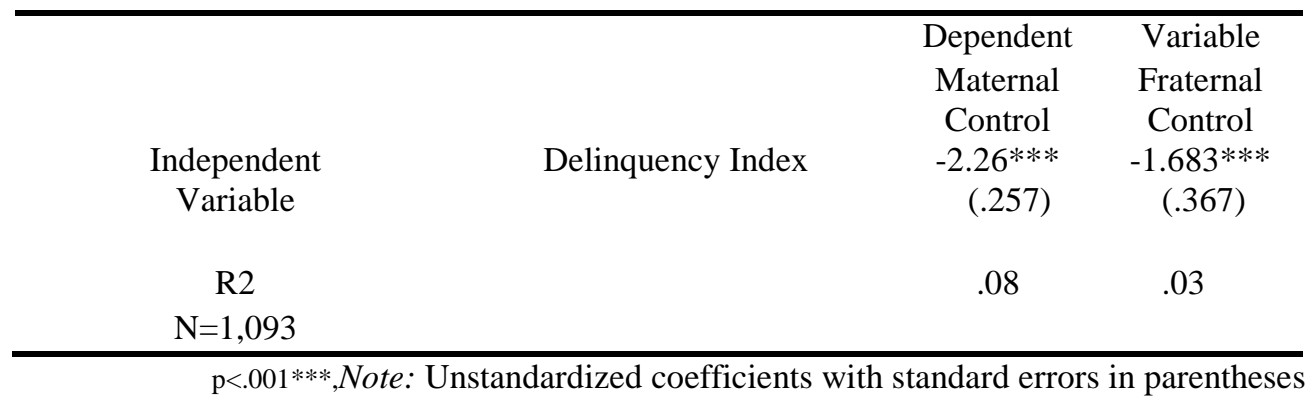

Future studies would benefit from a longitudinal data set, as it is likely the depression suggested by Sarah Rosenfield occurs later in life for females. While beyond the scope of this thesis, it has been suggested that research interested in the power-control theory should look at the adolescent's work force participation as a mediator (Uggen, 2000). Adolescent work force participation may influence depression as well by mediating the presence of patriarchy in the home. Research interested in depression and adolescents would be likely find varying results if the research was done looking at particular life moments. Experiencing traumatic or stressful life events will influence responses to a survey. For example, if a female experience a great loss she would be more likely to report being depressed or report a poor relationship with her parents. Other theories of delinquency suggest that it is also important to control for girls' bonds to their friends (Kerpelman \&Smight-Adcock, 2005). Both boys and girls tend to be affected by bonds to others, peers, school, parental control, and perceptions of risk taking (Steffenmeier \& Allan, 1996). Research that can examine this can help tease out the complicated relationship 
between parent and peer relationships, delinquency, and mental health. Other forms of family types should also be studied as the "one mother" and "one father" family do not make up the majority of households. Research on the power-control theory would benefit from looking at the possible differences between biological parents and step or adoptive parents as well as how patriarchy exists in same-sex parent households.

The Longitudinal Survey of Adolescent Health while widely used and respected data would benefit from questions assessing perceived patriarchy in the home. If questions about patriarchy were asked this research could open up the sample to include those respondents whose parents were unable to work due to injury or layoffs at work. The research could also include those from various family types like single parent homes and same-sex parent homes. Typical studies that test the powercontrol theory on single parent and same-sex parent homes view them as "egalitarian" but it is likely that various power-structures associated with parent workplace prestige still exists in these family types.

\section{$\underline{\text { Conclusions }}$}

This research aimed to further examine the effects of gender roles and social control on delinquency and mental health for adolescent females and add to the existing gap in literature on the female life course. The purpose of this research was to examine the power-control theory on adolescent female lives with an added interest in how the theory works for depression, thus suggesting a common etiology for delinquency and depression. A common origin for mental illness and delinquency would mean that gender difference in rates of mental illness and delinquency are due 
to the social roles ascribed to males compared to females. Additionally, a common etiology would suggest that research on mental illness and delinquency should not be studied outside of the social roles of the individual. This test of the power-control theory was innovative in that it tested a common theory of delinquency and hoped to expand the theory to test if the same could be said for depressive symptoms. This research is important in that it added to the validity of theoretical work done by Sarah Rosenfield by empirically testing her assertions on female risk taking and depression (1999).

The results of my thesis suggest that females' bonds to others are significant in predicting both depressive symptoms and delinquency. The power-control theory is correct in its inclusion of paternal relational control as a relevant variable since it yielded significant findings in this research. Risk-taking as positive behaviors needs to be studied extensively as this thesis found higher tastes for risk is associated with lower depression symptoms for adolescent females. The findings were consistent with other research that shows that those low levels of autonomy report more internalizing disorders (Marsh et al., 2003). Finally, although the precise mechanism for this relationship is beyond the scope of this analysis, the mother-daughter relationship appears to be instrumental in laying the foundation for further research on female adolescent delinquency and mental health.

These findings have several implications for interventions to reduce internalizing and externalizing disorders for female adolescents. This thesis helped to identify at-risk groups who would be in need of intervention. Those females who have 
weak bond to their parents are at most risk for engaging in delinquent behaviors and depression. Past research has indicated that females experience higher rates of selfesteem when the mother-daughter relationship is stong (Bynum \& Kotchich 2006).

Additionally, non-white females experience connections to parents differently. When controlling for paternal relational control, race still predicts an adolescent female engaging in delinquent behavior. The relationship between race and delinquency should be explored because as discovered in this thesis cultural ideals associated with femininity seem to differ along racial lines. 


\section{Works Cited}

Aarons, G.P, Brown, S.A., Hough, R. L., Garland, A.F., \& Wood, P.A. (2001). Prevalence of adolescent substance use disorders across five sectors of care. Journal of the American Academy of Academy of Adolescent, 40, 419-426.

Allison, K. R., Adalf, E. M., \& Mates, D. (1997). Life strain, coping, and substance use among high school students. Addiction Research, 5, 251-272.

Anderson, Elijah.1990. Streetwise. New York: W.W. Norton.

Anderson, Elijah. 1999. Code of the Street: Decency, Violence, and the Moral Life of the Inner City. New York: W.W. Norton.

Aneshensel, Carol. (1992). "Social Stress: Theory and Research." Annual Review of Sociology, 18, 15-38.

Avison, William R. and Donna D. McAlpine. (1992. "Gender Differences in Symptoms and Depression Among Adolescents." Journal of Health and Social Behavior, 33, 77-96.

Barnett, Peter A. and Ian H. Gottlib. (1988). "Psychosocial Functioning and Depression: Distinguishing Among Antecedents, Concomitants, and Consequences." Physiological Bulletin. 104, 97-126.

Birmahar, B., Ryan, N.D., Williamson, D.E., Brent, D.A., Kaufman, J., Daul, R.E., ...Nelson, B. (1996). Childhood and adolescent depression: A review of the past ten years. Part I. Journal of the American Academy of Child and Adolescent Psychiatry, 29, 914-918.

Blackwell, B.S. (2000). Perceived sanctions threats, gender, and crime: A test and elaboration of Power-control theory. Criminology. 38:439-488.

Cauffman, E., Lexcen, F.J., Goldweber, A., Shulman, E.P., \& Grisso, T. (2007). Gender Differences in mental health symptoms among delinquent and community youth. Youth Violece and Juvenile Justice, 5, 287-307.

Cernkovich, S. A., \&Giordano, P.C. (1987). Family relationships and delinquency. Criminology, 25, 295-321.

Chantala, K., \& Taylor, J. (2010). Strategies to perform design-based analysis using the Add Health Data. http://www.cpc.unc.edu/projects/addhealth

Cohen, P., Cohen, J., Kasen, S., Valez, C.N., Hartmark, C., Johnson, J., ...Streuning, E.L. (1993). An epidemiological study of disorders in late childhood and adolescence: I. Age and Gender-Specific Prevalence. Journal of Psychiatry and Psychology, 34, 851-867.

De Coster, S. (2005) Depression and law violation: Gendered responses to gendered stresses. Sociological Perspectives, 48, 155-187. 
Garland, A.F., Hough, R.L., McCabe, K. M., Yeh, M., Wood, P.A.,\& Aarons, G.P. (2001). Prevalence of psychiatric disorders in youth across five sectors of care. Journal of the American Academy of Adolescent Psychiatry, 40, 409-418.

Gilligan, C. (1982). In a different voice. Cambridge, MA: Harvard University Press.

Girls Incorporated. (1996). Prevention and parity: Girls in Juvenile justice. Indianapolis, IN: Author.

Grasmick, H.G., Hahan, J., Sims Blackwell, B., \& Arneklev, B.J. (1996). Risk preferences and patriarchy: Extending Power-Control Theory. Social Forces, 71, 177-199.

Gove, W., \& Crutchfield, R. (1982). The family and juvenile delinquency. Sociological Quarterly, 23, 301-319.

Hagan, J., Gillis, A.R., \& Simpson, J. (1985). The class nature of gender and delinquency: Toward a power-control theory of common delinquent behavior. American Journal of Sociology, 90, 1151-1178.

Hagan, J., Gillis, A.R., \& Simpson, J. (1990). Clarifying and extending the powercontrol theory. American Journal of Sociology, 95, 1024-1037.

Hagan, J., Gillis, A.R., \& Simpson, J. (1993). The power of control in sociological theories of delinquency. In F. Adler \& W. Laufer (Eds.) New directions in criminological theory (pp.381-398). New Brunswick, NJ: Transaction.

Hagan, J., Gillis, A.R., \& Simpson, J. (1987). Class in the household: A power-control theory of gender and delinquency. American Journal of Sociology, 92, 788816.

Hagan, John. (1987). Class in the Household: A power-control theory of gender and delinquency. American Journal of Sociology 92:788-816.

Hagan, J. (1987). Structural criminology. New Brunswick, NJ: Rutgers University Press.

Hagan, J., \& Foster, H. (2001). Youth violence and the end of adolescence. American Sociological Review, 66, 874-899.

Hagan, J., \& Foster, H. (2003). S/he's a rebel: Toward a sequential stress theory of delinquency and gendered pathways to disadvantage in emerging adulthood. Social Forces, 82, 32-86.

Hagan, J.,McCarthy, B., \& Foster, H. (2002). A gendered theory of delinquency and despair in the life course. Acta Sociologica, 45, 37-46.

Harris, Kathleen Mullan. 2009. The National Longitudinal Study of Adolescent Health (Add Health), Waves I \& II, 1994-1996; Wave III, 2001-2002; Wave IV, 2007-2009 [machine-readable data file and documentation]. Chapel Hill, NC: Carolina Population Center, University of North Carolina at Chapel Hill. 
Harlod, G. Grasmick, John Hagan, Brenda Sims Blackwell, Bruce J. Arneklev. 1996. Risk Preferences and Patriarchy: Extending the Power-Control Theory. Social Forces. 75-1.

Haynie, D.L., Giodano, P.C., Manning, W.D., \& Longmore, M.A.(2005). Adolescent romantic relationships and delinquency evolvement. Criminology, 43, 177-210.

Heimer, K., DeCoster, S., \& Unal, H. (2006). Opening the black box: Understanding the social psychology of the gender gap in delinquency. Sociology of Crime, Law, and Deviance, 7, 109-135.

Jensen, G.F.,\&Thompson, K. (1990). What's class got to do with it: A further test of the Power control theory.Am. J. Social. 96:1009-1023.

Jett, Joan. Bad Reputation. Boardwalk Records, 1981

Jordan, J.V. (1997). The relational model is a source of empowerment for women. In M.R.Walsh (Ed.).Women, men, and gender: Ongoing debates (pp. 373-382). New Haven, CT: Yale University Press.

Kazdin, A. E. (2000) Developing a research agenda for child and adolescent psychotherapy. Archives of General Psychiatry 57 , pp. 829-835.

Kerpelman, Jennifer L., \& Smith-Adcock, Sondra. (2005). Female Adolescents' Delinquent Activity: The intersection of Bonds to Parents and Reputation Enhancement. Youth and Society, 37;176.

Kessler, R.C., Berglund, P., Demler, O., Jin, O., Merikangas, K. R., \&Walters, E.E. (2009). Life-time prevalence and age-of-onset distributions of DSM-IV disorders in the National Comorbidity Survey Replication. Archives of General Psychiatry, 62, 593-602

Kessler, R.C., \& McLeod, J.D. (1984). Sex differences in vulnerability to undesirable life events. American Sociological Review, 49, 620-631.

Kort-Butler, L. (2009). Coping styles and sex difference in depressive symptoms and delinquent behavior. Journal of Youth and Adolescence, 38, 122-136.

Loeber, R., Farrington, D.P., Stouthamer-Loeber, M., and van Kammen, W.B. (1998). Antisocial behavior and mental health problems: Explanatory factors in childhood and adolescence. Mahwah, NJ: Lawrence Erlbaum.

Mack, K.Y.; Leiber, M.J., "Race, gender, single-mother households, and delinquency: A further test of power-control theory." Youth and Society. Dec 2005, 37, (2), $115-144$.

McCarthy, B., Hagan, J., \& Woodward, T.S.(1999) In the company of women: Structure and agency in a revised power-control theory of gender and delinquency. Criminology, 37, 761-788.

Miller, M.H., Esbensen, F., \& Freng, A. (1999). Parental attachment, parental supervision and adolescent deviance in intact and non-intact families. Journal of Crime and Justice. 22, 1-29.

Rosenfield, S. (1999). Gender and mental health: Do women have more psychopathology than men more or both the same (and why)? In A.V. Horwitz \& T.L. Scheid (Eds.), The handbook of the study of mental health: Social 
contexts, theories, and systems (pp.348-360). Cambridge: Cambridge University Press.

Rosenfield, S., Lennon, M., Raskin White, H. (2005). The Self and Mental Health: Self-Salience and the Emergence of Internalizing and Externalizing Problems. Journal of Health and Social Behavior.46, 323-340.

Rutter, M. (1986). Child psychiatry: The interface between clinical and developmental research. Psychological Medicine, 16, 151-169.

Rutter, M. (1989). Isle of Write revisited: Twenty-five years of child psychiatric epidemiology. Journal of the American Academy of Child and Adolescent Psychiatry, 28, 633-655.

Seiffge-Krenke, I., \& Klessinger, N. (2000). Long term effects of avoidant-coping on adolescents' depressive symptoms. Journal of Youth and Adolescence, 29, 617-630.

Steffensmeier, D., \& Allen, E. (1996). Gender and crime: Toward a gendered theory of female offending. Annual Review of Sociology, 22,459-487.

Van Gundy-Yoder, A.L., (2006). "Gender and parental attachment: An examination of delinquency across the life course." Presented at the Academy of Criminal Justice Sciences, Academy of Criminal Justice Sciences, Seattle, WA, Mar 2007.

Van Gundy-Yoder, A.L.,(2007). "Parental attachment and delinquency: Does gender really matter." Presented at the American Society of Criminology, American Society of Criminology.

Van Voorhis, P., Cullen, F.T., Mathers, R.A. \&Garner, C.C. (1988). The impact of family structure and quality on delinquency: A comparative assessment of structural and functional factors. Criminology, 26, 235-261.

Vincent, G.M., Grisso, T., Terry, A., \& Banks, S. (2008). Sex and race differences in mental helath symptoms in juvenile justice: The MAYSI-2 national metaanalysis. Journal of American Academy of Child and Adolescent Psychiatry, 47, 282-290.

Walker, Charlotte Elaine, "Mother Daughter Relationships and Female Adolescent Sexual Behavior." Dissertion, University of Michigan, 2005

Wareham, J., and Paquette-Boots, D. (2011). Gender differences in mental health problems and violence among Chicago youth. Youth Violence and Juvenile Justice. 9,3-22.

Warren, K., "Family Structure and Attachment and Their Role in Reducing Delinquency in the African American Family." Dissertation, Western Michigan University, 2002. 